\title{
Recommendations for processing atmospheric attenuated backscatter profiles from Vaisala CL31 ceilometers
}

\author{
Simone Kotthaus ${ }^{1}$, Ewan O'Connor ${ }^{1,2}$, Christoph Münkel $^{3}$, Cristina Charlton-Perez ${ }^{4}$, Martial Haeffelin ${ }^{5}$, \\ Andrew M. Gabey ${ }^{1}$, and C. Sue B. Grimmond ${ }^{1}$ \\ ${ }^{1}$ Department of Meteorology, University of Reading, Reading, RG6 6BB, UK \\ ${ }^{2}$ Finnish Meteorological Institute, 00101 Helsinki, Finland \\ ${ }^{3}$ Vaisala GmbH, 22607 Hamburg, Germany \\ ${ }^{4}$ Met Office, Meteorology Building, University of Reading, Reading, RG6 6BB, UK \\ ${ }^{5}$ Institute Pierre Simon Laplace, Centre National de la Recherche Scientifique, École Polytechnique, \\ 91128 Palaiseau, France
}

Correspondence to: Simone Kotthaus (s.kotthaus@reading.ac.uk)

Received: 14 March 2016 - Published in Atmos. Meas. Tech. Discuss.: 29 March 2016

Revised: 12 July 2016 - Accepted: 20 July 2016 - Published: 17 August 2016

\begin{abstract}
Ceilometer lidars are used for cloud base height detection, to probe aerosol layers in the atmosphere (e.g. detection of elevated layers of Saharan dust or volcanic ash), and to examine boundary layer dynamics. Sensor optics and acquisition algorithms can strongly influence the observed attenuated backscatter profiles; therefore, physical interpretation of the profiles requires careful application of corrections. This study addresses the widely deployed Vaisala CL31 ceilometer. Attenuated backscatter profiles are studied to evaluate the impact of both the hardware generation and firmware version. In response to this work and discussion within the CL31/TOPROF user community (TOPROF, European COST Action aiming to harmonise ground-based remote sensing networks across Europe), Vaisala released new firmware (versions 1.72 and 2.03) for the CL31 sensors. These firmware versions are tested against previous versions, showing that several artificial features introduced by the data processing have been removed. Hence, it is recommended to use this recent firmware for analysing attenuated backscatter profiles. To allow for consistent processing of historic data, correction procedures have been developed that account for artefacts detected in data collected with older firmware. Furthermore, a procedure is proposed to determine and account for the instrument-related background signal from electronic and optical components. This is necessary for using attenuated backscatter observations from any CL31 ceilometer. Recommendations are made for the processing of attenuated
\end{abstract}

backscatter observed with Vaisala CL31 sensors, including the estimation of noise which is not provided in the standard CL31 output. After taking these aspects into account, attenuated backscatter profiles from Vaisala CL31 ceilometers are considered capable of providing valuable information for a range of applications including atmospheric boundary layer studies, detection of elevated aerosol layers, and model verification.

\section{Copyright statement}

The works published in this journal are distributed under the Creative Commons Attribution 3.0 License. This license does not affect the Crown copyright work, which is re-usable under the Open Government Licence (OGL). The Creative Commons Attribution 3.0 License and the OGL are interoperable and do not conflict with, reduce or limit each other.

() Crown copyright 2016

\section{Introduction}

Ceilometer lidars are widely used to characterise clouds (Illingworth et al., 2007). Sophisticated cloud base height detection is found to provide reliable estimates, with multiple cloud layers identified (Martucci et al., 2010). Although 
originally developed as "cloud base recorders", attenuated backscatter profiles from ceilometers can also provide information on rainfall (Rogers et al., 1997), formation and clearance of fog (Haeffelin et al., 2010), drizzle properties (when combined with cloud radar; O'Connor et al., 2005), and for the study of aerosols, including elevated layers of Saharan dust (Knippertz and Stuut, 2014), biomass burning (Mielonen et al., 2013) or volcanic ash (e.g. Marzano et al., 2014; Nemuc et al., 2014; Wiegner et al., 2012), and particles dispersed within in the atmospheric boundary layer (ABL) (Tsaknakis et al., 2011). Using aerosols as a tracer, boundary layer dynamics, including mixing height and the formation of residual layers, can be inferred from ceilometer attenuated backscatter observations (e.g Münkel et al., 2007; Stachlewska et al., 2012; Selvaratnam et al., 2015). As they can operate automatically for long periods without maintenance or human intervention even in extreme climates (Bromwich et al., 2012), they are widely deployed operationally by national meteorological services (NMS, e.g. http://www.dwd.de/ceilomap) and long-term research campaigns (e.g. http://micromet.reading.ac.uk).

Although ceilometers are regarded as the most basic automatic lidars (Emeis, 2010), they detect the location and extent of aerosol layers and can be used to derive the aerosol backscatter coefficient, provided signal-to-noise ratio (SNR) is sufficient and a careful calibration is applied (e.g. Jenoptik CHM15K; Heese et al., 2010; Wiegner et al., 2014). Observations from ceilometers are highly valuable for the evaluation of numerical weather prediction (NWP) and air-quality models (Emeis et al., 2011b) and are increasingly used in forecast verification. Several NMS and research centres are currently evaluating the potential of using ceilometer profile observations for data assimilation (Illingworth et al., 2015).

This wide range of applications requires careful quality control of the observed attenuated backscatter to ensure reliable data for analysis. The European COST Action TOPROF (http://www.toprof.imaa.cnr.it/) works in close collaboration with E-Profile (http://www.eumetnet.eu/e-profile) to develop protocols for quality assurance and quality control (QAQC; Illingworth et al., 2015) of observations from automatic lidars and ceilometers (ALCs). The E-Profile programme of the Network of European Meteorological Services (EUMETNET) aims to facilitate the exchange of observational data by harmonising the ALC networks across Europe. As ceilometers are manufactured by several companies, the sensor optics, hardware components, and software algorithms may differ significantly. Discussions in the TOPROF community have revealed the importance of a detailed understanding of instrument specifics to identify the necessary processing steps enabling appropriate interpretation and harmonisation of the final data products. For example, the extensive CeiLinEx2015 intercomparison campaign (http: //www.ceilinex2015.de) was devised by TOPROF members to evaluate attenuated backscatter and cloud base height products from a range of ceilometer models from several manufacturers (including Lufft/Jenoptik, Campbell Scientific, and Vaisala). This study addresses the commonly deployed Vaisala CL31 ceilometer. Earlier Vaisala ceilometer models include LD40 and CT25K; the CL51 is the most recent model.

Emeis et al. (2011a) report that attenuated backscatter from Vaisala CL31 ceilometers portrays structures in the ABL consistent with temperature and humidity profiles observed by radiosondes and a sodar RASS system. Initial evaluation of CL31 attenuated backscatter observations for quantitative aerosol analysis (Sundström et al., 2009) suggests accuracy might be sufficient in the ranges near the instrument if certain systematic artefacts found in the profiles can be removed or accounted for. McKendry et al. (2009) find that, under clear-sky conditions, the CL31 has the capability to "detect detailed aerosol layer structure (such as fire or dust plumes) in the lower troposphere" that is consistent with the aerosol structure detected by an aerosol research lidar (CORALNet-UBC). However, comparing a Vaisala LD40 and two CL31 ceilometers, Emeis et al. (2009) show that attenuated backscatter may vary distinctly between these sensors. The differences found cannot be explained by a lack of absolute calibration as they are manifested in vertical structures rather than as a simple offset. Instrumentspecific signatures may have implications for the representation of ABL structures. Emeis et al. (2009) state "internally generated artefacts from the instrument's software" could play a role, but they refrain from providing further details. While software-related artefacts might contribute to the differences, the discrepancy between the attenuated backscatter profiles observed by the two CL31 sensors tested (Emeis et al., 2009) might also be explained by the hardware-related (electronic or optical) background signal. Recent work on a Halo Doppler lidar suggests such background signal features could be corrected for during post-processing (Manninen et al., 2016).

Incomplete optical overlap can be corrected for, but uncertainties may remain. Recent research shows, for example, that the overlap function of a Lufft CHM15K is slightly temperature dependent (Hervo et al., 2016). Due to the co-axial beam design, the full optical overlap for the CL31 is reached at low ranges (Münkel et al., 2009), which can be beneficial when studying meteorological processes in the lowest part of the atmosphere, such as fog, haze, or aerosols emitted at the Earth's surface. For example, in comparison to an LD40 which reaches complete overlap only at $200 \mathrm{~m}$, the CL31 has an advantage in detecting low, stable layers (Emeis et al., 2009). Although Vaisala suggests that the attenuated backscatter profile is reliable down to the first range gate, Sokół et al. (2014) document a distinct local minimum in CL31 attenuated backscatter observations at the fourth range gate persisting throughout their entire observational campaign. As others have found artefacts in CL31 profiles below $70 \mathrm{~m}$ (e.g. Martucci et al., 2010; Tsaknakis et al., 2011), these lowest ranges are often excluded from analysis. Sundström 
et al. (2009) evaluate the applicability of CL31 observations for quantitative aerosol measurements and conclude that the artefacts in the range gates near the instrument are a major source of uncertainty. Van der Kamp (2008) smooths out systematic artefacts by strong vertical averaging; however, this removes the possibility of identifying any atmospheric features close to the surface.

Various techniques have been developed to infer the mixing height from the shape of the attenuated backscatter profiles from ceilometers (Emeis et al., 2008; Haeffelin et al., 2012). While detection algorithms vary, all methods exploit the fact that aerosol concentrations (and atmospheric moisture if boundary layer clouds are absent) are typically significantly higher in the ABL compared to the free atmosphere above. This causes a distinct decrease in attenuated backscatter at the boundary layer top, provided that the SNR is sufficiently large up to this height.

A series of studies have successfully used CL31 observations to detect mixing height (e.g. Münkel et al., 2007; van der Kamp and McKendry, 2010; Eresmaa et al., 2012; Sokół et al., 2014; Tang et al., 2016), often reporting an increased performance under convective conditions that ensure the backscattering aerosols are well dispersed. However, Eresmaa et al. (2012) report that fitting an idealised profile to the observed attenuated backscatter from a CL31 may be challenging where noise levels are high. As the CL31 operates with a very low-powered laser, its noise levels may be higher than that found for other ALC systems (cf. Jenoptik CHM15K; Haeffelin et al., 2012). Madonna et al. (2015) evaluate the profiling ability of several ALCs from different manufacturers (i.e. Jenoptik CHM15K, Vaisala CT25K, and Campbell CS135s) against a MUSA advanced Raman lidar during night-time. They conclude that the attenuated backscatter coefficient generally is in good agreement with the reference measurement for the CHM15K, while the CS135s shows good agreement only for small values and the CT25K tends to underestimate, which may be related to the overall lower SNR of the latter two sensors. If noise levels are too high within the ABL, as reported e.g. by Haeffelin et al. (2012) for a case study using a Vaisala CL31 ceilometer at the SIRTA site near Paris, the signal might not be sufficient to detect the top of the ABL. De Haij et al. (2006) apply an SNR threshold to restrict observations from a Vaisala LD40 ceilometer to be used for mixing height detection. Such filtering based on SNR diagnostics presents a useful tool to differentiate measurements containing significant atmospheric signal from observations dominated by instrument noise and atmospheric noise induced by solar radiation.

Neither the SNR nor the noise inherent in each profile is provided in the output of ALCs. Xie and Zhou (2005) propose a method for SNR calculations for lidar observations whereby the signal profile is approximated by a linear fit to the readily averaged profile along set range bins and assigning the deviations from that fit to the noise. Markowicz et al. (2008) apply this method to observations of a Vaisala
CT25K averaged over $200 \mathrm{~s}$. These SNR values indicate that the observations are only reliable within the ABL (absence of clouds) and it is stated that an SNR $=10$ marks "a limiting value of detection" (Markowicz et al., 2008). Assuming there are no temporal variations in the atmosphere probed by several consecutive observations (e.g. over a few minutes), the standard deviation at each range gate could be used as a noise estimate of the respective average if high-temporalresolution measurements are recorded (Xie and Zhou, 2005). Assuming the noise is range-invariant before the range correction, a noise estimate for the whole profile could be estimated based on observations where the signal contribution is negligible, e.g. based on the topmost range gates under the absence of high clouds and aerosol layers. Heese et al. (2010) use the highest range gates to calculate a noise value for each profile for a Jenoptik CHM15K, assuming the signal noise follows Poisson statistics as typically assumed for photon counting detectors. Vaisala sensors operate with an avalanche photodiode (APD), so that the noise cannot be interpreted as a counting error. The SNR increases significantly when highresolution observations are averaged over certain time and/or range windows. Using a Gaussian smoothing method on observations of a Jenoptik CHM15K, Stachlewska et al. (2012) find that the SNR significantly increases if the width of range windows is increased linearly. However, they remark that this may result in extensive computing time. In addition, excessively large smoothing windows may reduce the detectability of sharp features (Haeffelin et al., 2012).

Despite the evidence that attenuated backscatter profiles are a complex data product that might have to be carefully evaluated before being used to draw conclusions on the probed atmosphere, no guidelines are available to ensure systematic QAQC. This study documents the important processing steps that should be considered when analysing attenuated backscatter profiles from Vaisala CL31. Observations from three ALC networks (Sect. 2) are used to illustrate relevant data processing aspects (Sect. 3). Depending on the firmware version, the CL31 instrument internal processing may introduce certain artefacts that should be accounted for if the attenuated backscatter is required for analysis. It is shown how the signal strength can be used for quality assurance (Sect. 4) and findings are summarised in the form of recommendations for the processing of CL31 profile observations (Sect. 5).

\section{Instrument description}

The Vaisala CL31 transmits a very short pulse of $110 \mathrm{~ns}$ (corresponding to an effective pulse length of about $16.5 \mathrm{~m}$; e.g. Weitkamp, 2005). The receiver uses an APD detector to record the returned signal. The instrument oversamples the backscattered signal at a temporal rate, which corresponds to the range resolution setting. The reported range $r$ (i.e. distance from the instrument) denotes the centre of a range gate. 
Gaussian low-pass filtering of $3 \mathrm{MHz}$ by the instrument extends and shapes the pulse response. Different vertical resolutions can be achieved depending on the sample rate. For example, a sample rate of $15 \mathrm{MHz}$ is required to achieve a range resolution of $10 \mathrm{~m}$, where the first observation reported at $10 \mathrm{~m}$ is backscattered signal for $5-15 \mathrm{~m}$ from the ceilometer. Every $2 \mathrm{~s}, 2^{14}$ laser pulses are emitted with a frequency of $10 \mathrm{kHz}$, which takes about $1.64 \mathrm{~s}$. After this period there is an idle time of $0.36 \mathrm{~s}$ used to perform the cloud base detection algorithm before the next set of $2^{14}$ laser pulses is emitted. After a certain number of gates have been sampled, the firmware slightly changes operation mode; thus, regions of increased noise are introduced into the backscatter profiles at two ranges: $\sim 4940$ and $\sim 7000 \mathrm{~m}$. Samples collected during the $2 \mathrm{~s}$ intervals are averaged over certain internal intervals to create the reported signal at a rate defined by the reporting interval selected by the user ( $2-30 \mathrm{~s})$. The internal averaging interval is specific to the firmware (see below).

The spectral wavelength of the laser diode used in the Vaisala CL31 is $905 \pm 10 \mathrm{~nm}$ at $298 \mathrm{~K}$, as stated by the laser manufacturer. Vaisala finds the uncertainty of the nominal centre wavelength to be well below $10 \mathrm{~nm}$. Typical spectral width (full width at half maximum, FWHM) is $4 \mathrm{~nm}$. Lasers produced from the same wafer agree in terms of the centre wavelength, but the exact centre wavelength is unknown to the user. For a specific laser the centre wavelength is slightly temperature dependent $\left(0.3 \mathrm{~nm} \mathrm{~K}^{-1}\right)$. The CL31 system heater near the laser transmitter serves to stabilise the laser temperature in cold environments. Further, both window transmission and laser pulse energy can have an impact on the attenuated backscatter signal. The laser heat sink temperature (denoted in the CL31 output as the "laser temperature"), window transmission, and laser pulse energy are therefore monitored and reported continuously. Status information (i.e. diagnostics, warnings, and alarms) is included in the data message, which helps to identify whether maintenance is required (e.g. window needs cleaning, transmitter is failing). In addition to the detected cloud base height, the CL31 can be set to report a profile of range-corrected "attenuated backscatter". However, as these values lack absolute calibration (see Sect. 4.1), observations are here referred to as the "reported range-corrected signal" (RCS; for details on range correction see Sect. 3.2).

The detector of the CL31 responds to the backscattering of the laser pulse from molecules, aerosols, rain drops, and both liquid and ice cloud particles. It also responds to noise originating from both external (e.g. daytime solar radiation) and internal (e.g. electronic) sources. The hardware-related noise is larger than the Rayleigh signal associated with clear air so that the latter is too small to be distinguished. Vaisala states that the variance of the electronic noise signal is range independent. The background light from solar radiation increases the current through the APD, but as the amplifiers are AC coupled, the relatively slowly varying solar signal (almost DC) does not get to the A/D converter. (The AC-
Table 1. Internal averaging interval applied in different CL31 firmware versions as a function of range $r$ and reporting interval.

\begin{tabular}{llllll}
\hline & & \multicolumn{4}{c}{ Reporting interval } \\
\hline Firmware version & Range $(\mathrm{m})$ & $2 \mathrm{~s}$ & $3-4 \mathrm{~s}$ & $5-8 \mathrm{~s}$ & $>8 \mathrm{~s}$ \\
\hline$<1.72,2.01,2.02$ & $r<600$ & $2 \mathrm{~s}$ & $4 \mathrm{~s}$ & $8 \mathrm{~s}$ & $16 \mathrm{~s}$ \\
& $600 \leq r<1200$ & $4 \mathrm{~s}$ & $4 \mathrm{~s}$ & $8 \mathrm{~s}$ & $16 \mathrm{~s}$ \\
& $1200 \leq r<1800$ & $8 \mathrm{~s}$ & $8 \mathrm{~s}$ & $8 \mathrm{~s}$ & $16 \mathrm{~s}$ \\
& $1800 \leq r<2400$ & $16 \mathrm{~s}$ & $16 \mathrm{~s}$ & $16 \mathrm{~s}$ & $16 \mathrm{~s}$ \\
$1.72,2.03$ & $r \geq 2400$ & $30 \mathrm{~s}$ & $30 \mathrm{~s}$ & $30 \mathrm{~s}$ & $30 \mathrm{~s}$ \\
& $r>0$ & $30 \mathrm{~s}$ & $30 \mathrm{~s}$ & $30 \mathrm{~s}$ & $30 \mathrm{~s}$ \\
\hline
\end{tabular}

coupling time constant is $1 \mathrm{~ms}$; i.e. the AC coupling works as a high-pass filter with $159 \mathrm{~Hz}$ corner $(-3 \mathrm{~dB})$ frequency.) This filtering results in a variable zero-bias level (i.e. noise has negative and positive values) that accounts for temporal variations in the atmospheric background signal. While the AC coupling removes the low frequency signal from varying solar radiation, the latter still increases signal noise (shot noise in APD due to DC current). For short data acquisition intervals, backscatter values can be below 0 . Electronic noise is also a function of system properties (e.g. detector temperature, transmitter lens area; Gregorio et al., 2007; Vande Hey, 2014) and can therefore be analysed by the manufacturer prior to field deployment. Heaters provide partial thermal stabilisation of the laser and detector system in cool or cold conditions.

The Vaisala CL31 firmware has been modified over time along with certain developments in the hardware, i.e. the receiver (CLR) and engine board (CLE) where the internal processing takes place. These updates have resulted in the creation of a range of firmware versions. For CLE311+CLR311, the firmware versions 1.xx are used, while sensors with CLE321 + CLR321 run firmware versions 2.xx. Changing the ceilometer transmitter (CLT) generation is not connected to a change in firmware. The internal averaging interval differs slightly with firmware version (Table 1). In Vaisala CL31 firmware versions below 1.72 and versions 2.01 and 2.02, the internal averaging interval is set to $16 \mathrm{~s}$ for range gates below $2400 \mathrm{~m}$ if the reporting interval is greater than $8 \mathrm{~s}$. For reporting intervals between 5 and $8 \mathrm{~s}$, the internal averaging interval is set to $8 \mathrm{~s}$ below $1800 \mathrm{~m}$ and $16 \mathrm{~s}$ between 1800 and $2400 \mathrm{~m}$. For reporting intervals below $5 \mathrm{~s}$ internal averaging below $1200 \mathrm{~m}$ is $4 \mathrm{~s}$; only for the minimum reporting interval of $2 \mathrm{~s}$ is internal averaging set to $2 \mathrm{~s}$ below $600 \mathrm{~m}$. Above $2400 \mathrm{~m}$, the internal averaging is $30 \mathrm{~s}$ for all reporting intervals. In firmware 1.72 and 2.03, the internal averaging interval is $30 \mathrm{~s}$ for the entire profile and does not change with reporting interval (Table 1). If a reporting interval is selected that is shorter than the internal averaging interval, consecutive profiles overlap in time and are hence not completely independent.

Observations from three ceilometer networks (Table 2) are used in this study to illustrate aspects of the data 
Table 2. Vaisala CL31 ceilometer specifications of sensor hardware, firmware, H2 noise setting, and resolution selected by the user. The term "H2" is discussed in Sect. 3.2.

\begin{tabular}{llllll}
\hline Sensor ID & Network & Ceilometer engine board/receiver/transmitter & Firmware version & H2 & $\begin{array}{l}\text { Resolution } \\
\text { (time, range) }\end{array}$ \\
\hline $\mathrm{A}$ & LUMO & CLE311/CLE311/CLT311 & $1.56,1.61,1.71$ & On & $15 \mathrm{~s}, 10 \mathrm{~m}$ \\
& & CLE311/CLE311/CLT321 & $1.71,1.72$ & On & $15 \mathrm{~s}, 10 \mathrm{~m}$ \\
$\mathrm{~B}$ & LUMO & CLE311/CLE311/CLT311 & 1.61 & On & $15 \mathrm{~s}, 10 \mathrm{~m}$ \\
& & CLE311/CLE311/CLT321 & $1.61,1.71,1.72$ & On & $15 \mathrm{~s}, 10 \mathrm{~m}$ \\
$\mathrm{C}$ & LUMO & CLE321/CLE321/CLT321 & $2.01,2.02,2.03$ & On & $15 \mathrm{~s}, 10 \mathrm{~m}$ \\
$\mathrm{D}$ & LUMO & CLE321/CLE321/CLT321 & $2.01,2.02,2.03$ & On & $15 \mathrm{~s}, 10 \mathrm{~m}$ \\
$\mathrm{~W}$ & Met Office & CLE311/CLE311/CLT311 & 1.71 & Off & $30 \mathrm{~s}, 20 \mathrm{~m}$ \\
$\mathrm{~S}$ & Meteo France & CLE321/CLE321/CLT321 & 2.01 & On & $30 \mathrm{~s}, 15 \mathrm{~m}^{*}$ \\
\hline
\end{tabular}

* Block averages of the recorded data $(2 \mathrm{~s}, 5 \mathrm{~m})$ are used for sensor $\mathrm{S}$.

acquisition and processing of Vaisala CL31. The London Urban Micromet Observatory (LUMO; http://micromet. reading.ac.uk) is a measurement network collecting observations of many atmospheric fields to investigate climate conditions within and around Greater London, UK (for interactive map see http://www.met.reading.ac. uk/micromet/LUMA/Network.html). The Met Office operates an ALC network (http://www.metoffice.gov.uk/public/ lidarnet/lcbr-network.html) across the UK with different manufacturers/models, including Vaisala CL31. A CL31 is operated by Meteo France at the SIRTA site at Palaiseau, France, for atmospheric research activities (Haeffelin et al., 2005; http://www.sirta.fr). Four sensors from the LUMO network in central London, one Met Office sensor located $60 \mathrm{~km}$ west of central London, and the Meteo France/SIRTA sensor are used here.

Long-term observations are available from four CL31 ceilometers with different generations of hardware and various firmware versions. Over time, the LUMO network firmware versions have changed from the first LUMO sensor deployed in 2006 with version 1.56 (Table 2). Sensors $\mathrm{A}$ and $\mathrm{B}$ are the old hardware generation with the CLE311 board, as is the Met Office sensor W, while LUMO sensors C and D and the SIRTA sensor S have engine boards CLE321. For both sensors A and B the transmitter has been upgraded from CLT311 to CLT321 during their operation, and for sensor $\mathrm{S}$ the transmitter CLT321 was replaced by a spare part of the same generation. While the LUMO sensors are set to acquire data every $15 \mathrm{~s}$ with a vertical resolution of $10 \mathrm{~m}$, data from the Met Office ceilometer have a resolution of $30 \mathrm{~s}$ and $20 \mathrm{~m}$, and the SIRTA ceilometer captures data every $2 \mathrm{~s}$ with a range resolution of $5 \mathrm{~m}$. Analysis presented here uses block averages over $30 \mathrm{~s}$ and $15 \mathrm{~m}$ of the SIRTA ceilometer data.

\section{Corrections}

\subsection{Background correction}

The backscattered signal detected by an ALC generally consists of actual signal contributions from atmospheric attenuation, the atmospheric background signal associated with scattered solar radiation, and the instrument-related background signal (Cao et al., 2013). Here, "background signal" is used to describe systematic contributions from solar radiation or instrument components (including hardware and software). The CL31 measurement design accounts for the temporal noise bias induced by varying solar radiation by introducing a variable zero-bias level (Sect. 2). The atmospheric background signal still contributes to the noise in the profile. On average, the RCS (labelled "range and sensitivity normalised attenuated backscatter" in CL31 output) is inherently corrected for the impact of atmospheric background signal $P^{\text {bga }}(r)$ and only the instrument-related background signal $P^{\text {bgi }}(r)$ needs to be accounted for to derive the backgroundcorrected signal $\hat{P}$ (for ALC terminology see also Mattis and Wagner, 2014). Given that the time dependence of the data acquisition is linked to the spatial domain, the instrumentrelated background signal may vary with range, while stabilisation procedures (e.g. heaters) aim to reduce its temporal variability. Here, as temporal signal variations due to the solar background light are removed, the remaining temporal variations are considered to represent noise both from hardware and atmospheric background signal.

The instrument-related background signal $P^{\text {bgi }}(r)$ can combine effects associated with the electronic or optical components and those associated with internal processing by the instrument. Vande Hey (2014) discusses effects related to electronic noise, including impulse response for a Campbell CS135s, a system very similar to the Vaisala CL31. A specific processing procedure implemented in some CL31 firmware versions was found to alter the profile of the background signal systematically and is here treated separately from $P^{\text {bgi }}(r)$. This processing shifts the signal artificially so 


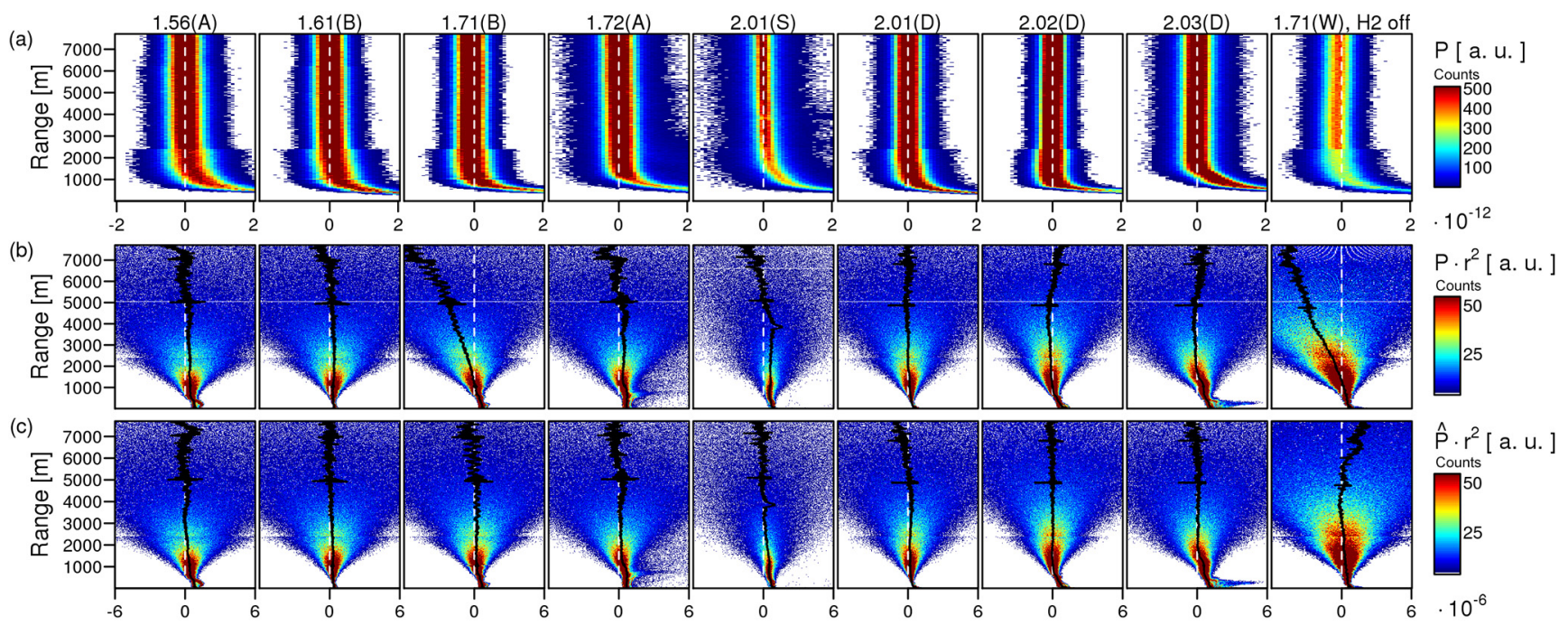

Figure 1. Range histograms for $24 \mathrm{~h}$ of observations from Vaisala CL31 ceilometers operating with firmware versions (1.56-2.03) on different clear-sky days. Sensor ID in brackets (see Table 2 for settings, e.g. H2 = off for sensor W). Rows: range histograms in arbitrary units (a. u.) of (a) signal $P$, (b) range-corrected signal reported $\mathrm{RCS}=P \cdot r^{2}$, and (c) range-corrected, background-corrected signal $\hat{P} \cdot r^{2}($ Sect. 3.1$)$. Median profiles (solid lines) are included in (b) and (c). The H2 setting (Sect. 3.2) allows switching off of the range correction above $2400 \mathrm{~m}$ for regions with no clouds present.

that the background signal of the respective data is biased and no longer centred on 0 (e.g. data collected with version 1.71 have more negative than positive values). This is applied to improve detection of cloud base height as it amplifies differences between the signal backscattered from cloud droplets and areas with low concentration of atmospheric scatterers where observations are dominated by noise. Increasing this difference facilitates visual interpretation of clouds based on the backscattered signal. Hereafter, this bias is referred to as "cosmetic shift" $P^{\mathrm{cs}}(r)$. Thus, to derive the entirely background-corrected signal from CL31 output, the complete background signal $P^{\mathrm{bg}}$, composed of range-dependent, instrument-related background signal $P^{\text {bgi }}(r)$ and the cosmetic shift $P^{\mathrm{cs}}(r)$, needs to be accounted for

$\hat{P}(r)=P(r)-P^{\mathrm{bg}}(r)=P(r)-P^{\mathrm{bgi}}(r)-P^{\mathrm{cs}}(r)$.

For data collected with firmware 1.72 or 2.03 , no cosmetic shift is incorporated ( $\left.P^{\mathrm{cs}}(r)=0\right)$, so that the complete background correction is represented by the range-dependent, instrument-related background signal $\left(P^{\mathrm{bg}}(r)=P^{\mathrm{bgi}}(r)\right)$. The impact of background signal and cosmetic shift on the reported signal is illustrated using observations from different clear-sky days (no elevated dust, aerosol layers, or cirrus) from CL31 sensors running a range of firmware versions (Fig. 1a). Under such conditions the only source of atmospheric signal above the ABL is very weak molecular and aerosol scattering. In practice, molecular scattering at the instrument wavelength is very weak, typically below the sensitivity of the instrument (Sect. 2), so that profiles consist only of the average total background signal and the noise. As the atmospheric background signal only contributes to the noise, no systematic differences in the shape of the observed profiles would be expected and obvious departures from 0 can be associated with data acquisition and processing, i.e. instrument-related background signal and potential cosmetic shift.

A suitable method to identify discrepancies in the profile shape is to create signal-range histograms (Fig. 1a) using $24 \mathrm{~h}$ (or more) of data. The most obvious effect revealed by the range histograms is a step change in the width of the distributions at $2400 \mathrm{~m}$ evident for all firmware versions, apart from 1.72 and 2.03. This step change is introduced by the averaging of the sampled signal that is applied internally by the instrument's firmware (Sect. 2, Table 1). The decrease in averaging time for range gates $<2400 \mathrm{~m}$ performed for earlier firmware increases the signal noise (see Sect. 4.2). Data acquired with version 1.72 or 2.03 are more consistent across all range gates as the whole profile is treated equally with an internal averaging interval of $30 \mathrm{~s}$.

The range histograms (Fig. 1a) show the impact of the incomplete background correction; i.e. instrument-related background signal and cosmetic shift are not accounted for. Both cause a systematic pattern in the observed profiles, illustrating the range dependence of the background signal. The cosmetic shift is particularly strong for version 1.71 . To capture both background effects, profiles are analysed during times when atmospheric variations are expected to be small and instrument conditions are stable (Fig. 2). $P$ profiles are extracted and averaged hourly when noise induced by solar radiation is absent ( $4 \mathrm{~h}$ around midnight), cloud cover is low $(<10 \%$ of the hour), no fog is present, the window trans- 


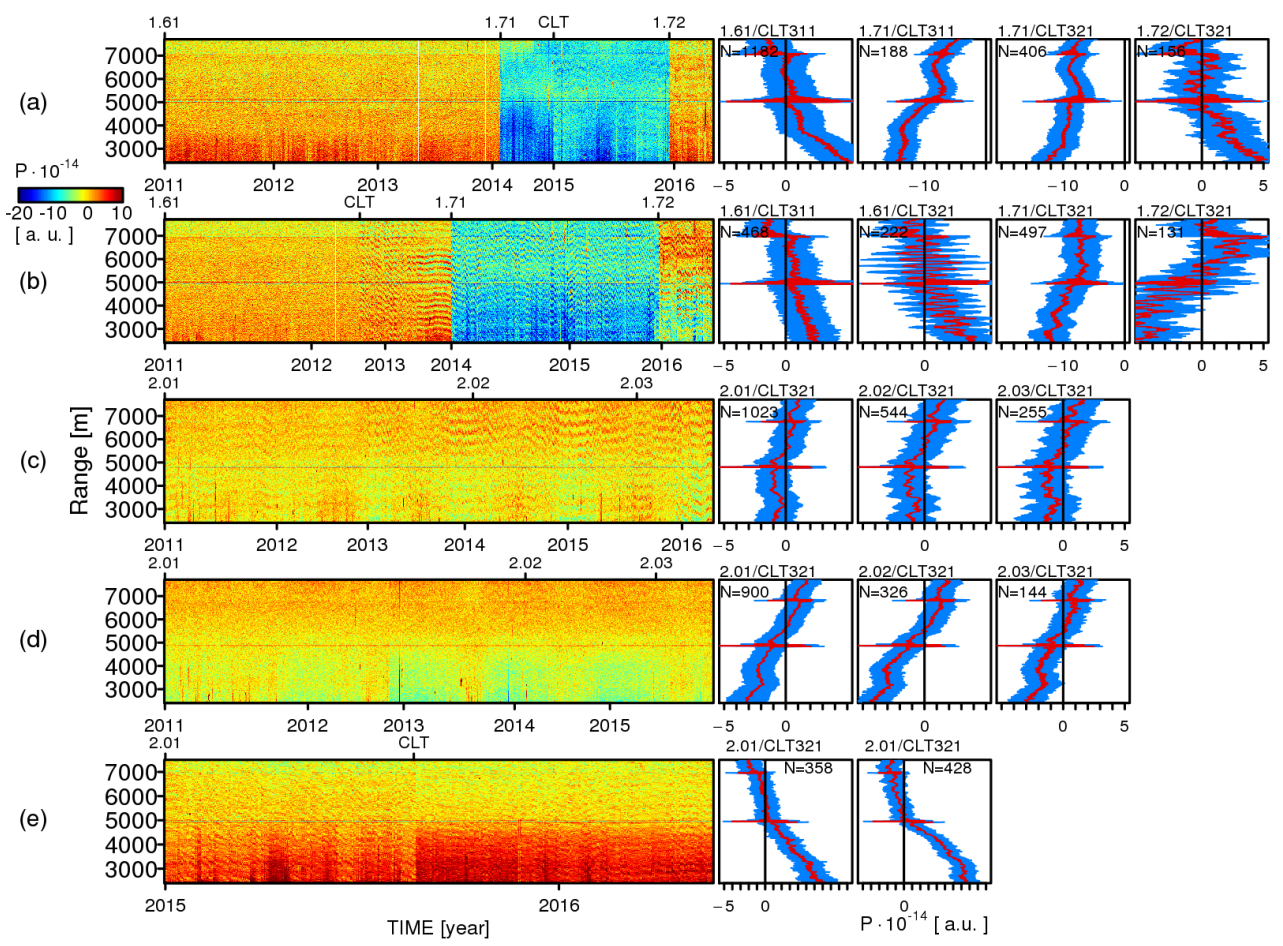

Figure 2. Signal $P$ (derived from reported signal by reverting range correction) observed with Vaisala CL31 sensors operating with (a, b) engine board CLE311 + receiver CLR311 (A, B) and (c, d, e) CLE321 + CLR321 (C, D, S), respectively (Table 2); (a-d) January 2011April 2016 and (e) May 2015-April 2016 for range $>2400 \mathrm{~m}$. Observations (4 h around midnight, 22:00-02:00 UTC) are hourly means of profiles when clouds detected for $<10 \%$ of the hour, no fog, average window transmission $>80 \%$, laser pulse energy $>98 \%$, and data availability $>90 \%$. Left: top axis shows firmware updates (version 1.71 , then 1.72 for sensors A and B; versions 2.02 , then 2.03 for $\mathrm{C}$ and D; version 2.01 for S) and hardware changes/upgrades (transmitter CLT311 replaced by CLT321 for sensors A and B; CLT321 replaced by a new CLT321 for sensor S). Right: median profiles (with IQR shading) of all selected observations grouped by firmware version and transmitter, with $N$ indicating the number of profiles.

mission is reasonable ( $>80 \%$ on average), laser pulse energy is high ( $>98 \%$ of nominal energy), and sufficient data are available ( $>90 \%$ of the hour; data gaps may occur due to maintenance or problems with data acquisition such as power cuts). Only range gates $>2400 \mathrm{~m}$ are analysed to avoid the impact of changing internal averaging intervals (Sect. 2) at this critical range (Fig. 1a) and to minimise the signal from the ABL (unlikely to extend above 2400 m over London around midnight). Median vertical profiles (with interquartile range (IQR) shading) are displayed for common setup conditions (Fig. 2, right), i.e. grouped by combinations of sensor, firmware, and transmitter (CLT). Engine board and receiver were not changed for any of the sensors during their operation.

The night-time profile climatology (Fig. 2) reveals a small temporal variability with a seasonal cycle (amplitude $\sim 50 \%$ ) that indicates a temperature dependence of the instrument-related background signal. Several features appear distinct in the spatial domain (Fig. 2) at certain range gates. For all sensors and firmware versions, a discontinuity is evident just below $5000 \mathrm{~m}$ and at around $7000 \mathrm{~m}$. These regions of increased noise are introduced by the data storage procedure (Sect. 2). Changing hardware components affects the instrument-related background signal even if the same model is swapped in. For example, exchanging the transmitter of sensor S by a part of the exact same model (CLT321 exchanged in September 2015, Fig. 2e) resulted in a clear increase of the background signal below about $4000 \mathrm{~m}$. As it cannot be guaranteed that the new transmitter has the exact same characteristics as the one replaced (Sect. 2), a slight change in wavelength might explain this shift.

For sensor B (Fig. 2b), the change in transmitter from CLT311 to CLT321 also altered the profile of the background signal, mainly by introducing a systematic pattern along the range. A wave-like structure appears superimposed over the random noise for ceilometer $\mathrm{B}$ when operating with transmitter CLT321 (Fig. 2b). A similar effect is detected in observations from ceilometer $\mathrm{C}$ in general (Fig. 2c) and to some extent in ceilometer $\mathrm{S}$ after the transmitter was changed (Fig. 2e). Such "ripple" patterns are introduced by a physical effect which overlays a vertically alternating positive and negative bias on top of the signal noise. While this wavetype bias tends to be similar for successive profiles (regions with positive and negative amplitude overlap), it is not en- 


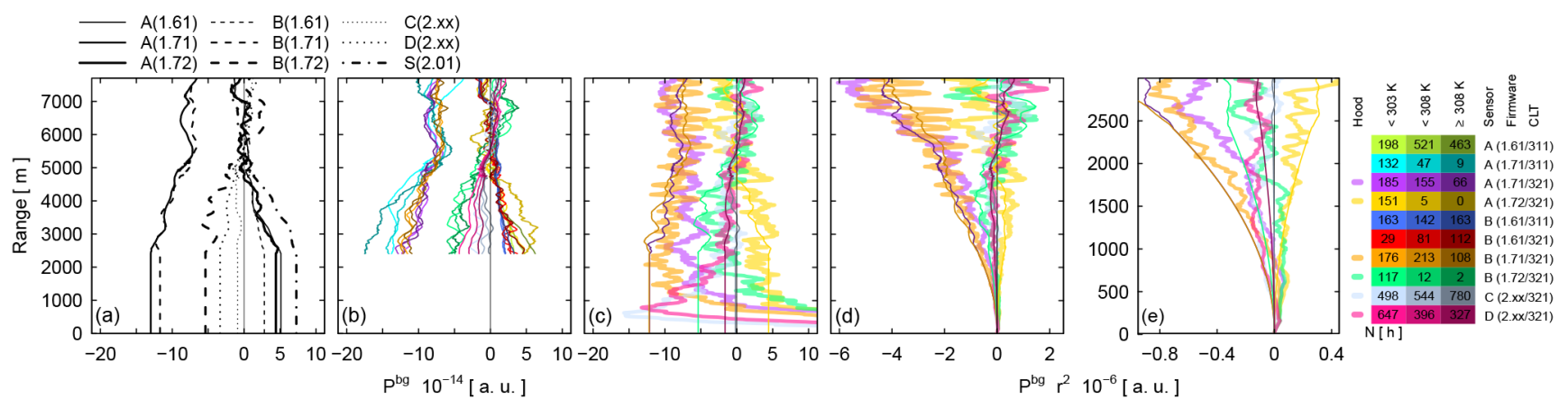

Figure 3. Long-term median vertical profiles of range-dependent, instrument-related background $P^{\text {bgi }}$ for Vaisala CL31 sensors (Table 2). Statistics are based on hourly mean profiles $(r>2410 \mathrm{~m})$ of the signal $P$ (derived from reported signal by reverting range correction) observed around midnight (same data as Fig. 2). Ceilometers A and B operated with firmware 1.61, 1.71, or 1.72 and transmitter type CLT311 or CLT321, respectively; ceilometers C and D operated with CLT321 and firmware 2.01, 2.02, and 2.03; ceilometer S operated with firmware 2.01 and CLT321. (a) Median profiles for each sensor calculated separately by firmware version for sensors A and B, all of which are combined for C and D (2.xx) due to their similarity. (b) As in (a) for sensors A, C, B, and D but also separating by ceilometer transmitter CLT and laser heat sink temperature combinations (see legend); laser heat sink temperature (reported by the ceilometer as laser temperature) is used to subdivide profiles into three classes ( $T_{\text {laser }}<303 \mathrm{~K}, 303 \mathrm{~K} \leq T_{\text {laser }}<308 \mathrm{~K}$, and $T_{\text {laser }} \geq 308 \mathrm{~K}$ ). (c) As in (b) but for selected profiles (solid lines, A and B with 1.71 and 1.72; C and D with 2.03) and their respective background profiles as determined by a 30 min termination hood measurement at the same setting and laser heat sink temperature class (thick lines). (d) As in (c) but range-corrected. (e) As in (d) but zoomed into the range $<3000 \mathrm{~m}$. Number of hourly mean profiles $N$ (h) available for each combination of sensor, firmware, transmitter type CLT, and laser heat sink temperature is listed in the legend. Profiles are smoothed vertically with a moving average over a window of $210 \mathrm{~m}$; only for profiles from sensor B is a smoothing window of $310 \mathrm{~m}$ used.

tirely constant over the course of a day because it is slightly affected by attenuation by clouds and ABL particles. As shown, this ripple is sensor specific (e.g. higher frequency detected for sensor B than C; Fig. 2b, c). While ripple may occur for ceilometers with both CLE311 + CLR311 (Fig. 2b) and CLE321 + CLR321 (Fig. 2c, e) engine board plus receiver combinations, only sensors operating a transmitter of type CLT321 were found to have the ripple effect (of those tested). The firmware version does not affect this wave-type bias as it is solely a hardware-related (electronic and/or optical) contribution to the background signal $P^{\text {bgi }}(r)$. At the time of publication of this paper, Vaisala could not fully explain the ripple effect. A possible correction for this ripple effect could be based on its sensor-specific frequency (as suggested by Frank Wagner, DWD, personal communication, 2015) but is not addressed here.

Assuming the actual information content related to atmospheric backscatter is low above the ABL in the selected night-time profiles (i.e. signal contribution is small cf. noise in the absence of clouds), the median climatology grouped by firmware plus transmitter configuration (Fig. 2, right) describes the background signal composed of instrumentrelated background signal and potential cosmetic shift (i.e. $\left.P^{\mathrm{bg}}(r)=P^{\mathrm{bgi}}(r)+P^{\mathrm{cs}}(r)\right)$. Although the range of values is large, IQR and median profiles have rather consistent statistics; the shape of the background signal profile depends on both sensor-individual hardware and firmware used. This is particularly evident when comparing median night-time climatology profiles for various configurations directly (Fig. 3).
The profiles for each sensor by firmware version (Fig. 3a) show that the complete background signal may be similar for sensors with the same generation of hardware (e.g. profiles of A and B, both with CLE 311+ CLR311, are similar when running firmware 1.61 or $1.71 ; \mathrm{C}$ and $\mathrm{D}$ are similar) but this is not necessarily the case (e.g. background signal of S operating with CLE321 + CLR321 clearly differs from the background signal detected for $\mathrm{C}$ and $\mathrm{D}$ ). Furthermore, the profile of the background signal may be altered by the firmware. For sensors analysed here, profiles of the background signal are positive $\left(\sim 2-5 \times 10^{-14}\right.$ arbitrary units (a.u.) at $2400 \mathrm{~m}$ ) below $7000 \mathrm{~m}$ for firmware 1.61, generally decreasing with altitude range. The step change when profiles change sign is also evident in the climatology of the night-time profiles (time series in Fig. 2). For all background signal profiles observed with firmware 1.71, a strong, negative bias $\left(\sim 12-14 \times 10^{-14}\right.$ a. u. at $\left.2400 \mathrm{~m}\right)$ associated with the applied cosmetic shift causes an overall negative background signal which increases (i.e. absolute values decrease) slightly with range below about $5500 \mathrm{~m}$. Background signal profiles from newer hardware (sensors C and D; Fig. 2c, d) can have a similar shape independent of firmware (i.e. 2.01, $2.02,2.03$ ). Nocturnal profiles of sensor S (Fig. 2e) show less variability compared to the LUMO sensors, which is explained by the fact that block averages $(30 \mathrm{~s} ; 15 \mathrm{~m})$ are analysed here instead of the high-resolution data $(2 \mathrm{~s} ; 5 \mathrm{~m})$ initially acquired (Table 2, Sect. 2). Generally, the combination of individual hardware components and firmware used appears to determine the background; i.e. while sensors A and 
$\mathrm{B}$ are in good agreement for data gathered with versions 1.61 or 1.71 , their backgrounds have opposite signs with version 1.72 .

The seasonality evident in the time series (Fig. 2c, d, left) is related to the laser heat sink temperature which is used to further classify the background signal of sensors A-D into three sub-classes (Fig. 3b, see legend). Profiles are only analysed above $2400 \mathrm{~m}$ as climatological measurements within the (sub-)urban ABL of London and Paris are inappropriate; if long-term measurements are available where ABL aerosol and moisture content are low (e.g. mountain sites), the climatology approach may provide valuable insights at lower range gates.

To evaluate whether the night-time climatology is a suitable basis to assess the background signal profile, test measurements for four LUMO sensors with recent firmware and hardware configurations are conducted (Fig. 3c). The ceilometer window is covered by a Vaisala termination hood to mimic full atmospheric attenuation (i.e. only little signal is backscattered to the receiver which is below the sensitivity of the detector). The recorded signal should represent internal contributions (e.g. background signal) only. To eliminate transient behaviour in the lowest range gates the hood measurements are taken for $30 \mathrm{~min}$ periods. Later tests indicate observations at range $<50 \mathrm{~m}$ may require about $1 \mathrm{~h}$ to settle to a characteristic value (Fig. 4), which is in agreement with CeiLinEx CL51 ceilometer termination hood measurements (Frank Wagner, DWD, personal communication, 2015; http://www.ceilinex2015.de). While variations above this range do not show a temporal drift, it is assumed that values in the first four range gates in the initial termination hood profiles are significantly overestimated. Here, the profile is therefore set to be constant below the fifth range gate (Fig. 3c-e).

Average termination hood profiles are compared to nighttime climatology profiles from the same laser heat sink temperature classes. For most sensors and firmware, the median night-time climatology agrees very well with the profile observed by the termination hood measurement (Fig. 3c). Only for ceilometer A (firmware 1.71) does the termination hood measurement have a slightly different shape, albeit with a similar order of magnitude. As there are no data available from the climatology approach for ranges below $2400 \mathrm{~m}$, profiles are assumed to be constant up to this range. While this results in an obvious discrepancy between the climatology-derived background and the termination hood profiles (Fig. 3c), implications of this assumption are greatly reduced after range correction is performed (Fig. 3d-e). Although uncertainties remain regarding the profiles of background signal below a range of $2400 \mathrm{~m}$, termination hood reference measurements give confidence that the night-time climatology measurements are not significantly influenced by backscatter from atmospheric particles and hence provide reasonable estimates of the background signal. This finding is extremely useful as it allows for the background signal of

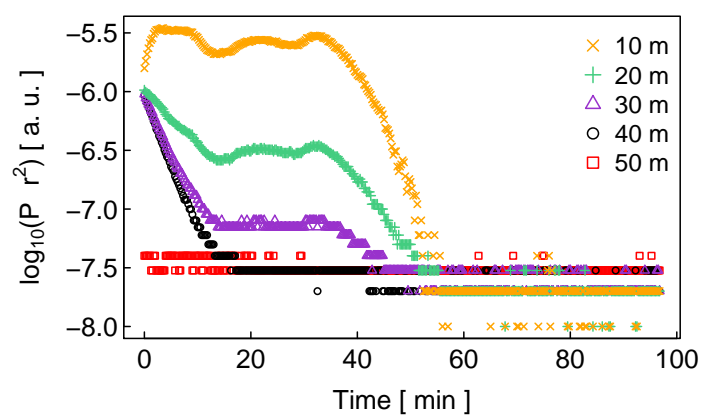

Figure 4. Logarithm of range-corrected signal reported $\mathrm{RCS}=$ $P \cdot r^{2}$ in the first five range gates during a termination hood measurement of LUMO sensor A with firmware 1.72.

ceilometer sites that were operated in the past or that are difficult to access (e.g. termination hood measurements are unfeasible) to be evaluated based on the observed profile data alone.

Vaisala states (firmware release note) that no deliberate cosmetic shift is implemented in versions 1.72 and 2.03 . Given that background signals from the earlier release versions are much closer to 0 or even positive, it can be concluded that there is no (or negligible) cosmetic shift in versions 1.56, 1.61, 2.01, and 2.02 and the complete background signal $P^{\mathrm{bg}}(r)$ is only composed of the instrumentrelated background signal $P^{\text {bgi }}(r)$. Of the versions tested, only firmware 1.71 profiles are shifted significantly towards negative values. The long-term estimates of hardwareand firmware-specific background signal $P_{\text {night }}^{\text {bg }}$ (instrumentrelated effects plus cosmetic shift; Fig. 3a) are used to determine an appropriate background correction:

$P_{\text {night }}^{\mathrm{bg}}(r)=\left[P^{\mathrm{bgi}}(r)+P^{\mathrm{cs}}(r)\right]_{\mathrm{night}}$.

For firmware with no significant cosmetic shift, the atmospheric contribution to the background correction is negligible so that a static correction over time can be applied defined by the night-time profiles:

$P^{\mathrm{bg}}(r)=P^{\mathrm{bgi}}(r)=P_{\text {night }}^{\mathrm{bg}}(r)$.

As discussed, background profiles from sensors C and D have a small temperature dependence (Fig. 3b); however, the background signal of these sensors has an overall very small magnitude so that this thermal effect is considered negligible in the proposed correction (Eq. 3). Data with cosmetic shift (i.e. those collected with firmware 1.71) show strong diurnal variations in the signal background in response to background solar radiation. This indicates some contribution of the atmospheric background is retained in observations from this firmware version as the dynamic "zero-bias level" is effectively different from 0 (Sect. 2). Because this is performed internally by the firmware, the exact contribution of 
the atmospheric background signal is not available for postprocessing use. However, it can be approximated by the average signal $P^{\text {top }}(t)$ across the top range gates where the contributions from aerosol scattering to the signal can be deemed negligible. The calculation of $P^{\text {top }}(t)$ follows the approach taken to estimate the noise-floor $F(t)$ (i.e. cirrus clouds are masked out; Sect. 4.2). Only for data affected by the cosmetic shift (i.e. firmware 1.71) does $P^{\text {top }}(t)$ show significant values with a clear diurnal pattern that define the temporal variations of the background while the night-time background profiles (Eq. 2) determine its range dependence. To ensure the background correction $P^{\text {bg }}(r)$ remains close to the climatology $P_{\text {night }}^{\mathrm{bg}}(r)$ when solar radiation is absent, a nocturnal average $P_{\text {night }}^{\text {top }}$ (mean $P^{\text {top }}(t)$ of $4 \mathrm{~h}$ around midnight calculated for each day to be corrected) is subtracted:

$P^{\mathrm{bg}}(t, r)=P_{\text {night }}^{\mathrm{bg}}(r)-\left(P^{\mathrm{top}}(t)-P_{\text {night }}^{\text {top }}\right)$.

The derived background correction $P^{\text {bg }}(r)$ (according to Eq. (4) for firmware 1.71 and Eq. (3) for other versions tested) can be applied in the post-processing to estimate the entirely background-corrected signal $\hat{P}$ without effects of cosmetic shift from the data recorded (Eq. 1). This correction reduces the range dependence of the observed signal so that the range histograms of $\hat{P} \cdot r^{2}$ (Fig. 1c) are more symmetric around 0 than those of $P \cdot r^{2}$ (i.e. RCS, Fig. 1b) in all range gates in the free atmosphere; i.e. the median profile is close to 0 .

All ceilometers tested here have a non-zero background profile, which confirms analysis by the Met Office (termination hood measurements and case study analysis) giving a negative background for other CL31 sensors in their network (Mariana Adam, Met Office, personal communication, 2014-2015). This creates additional challenges when deriving the aerosol backscatter coefficient from such measurements (Mariana Adam, Met Office, personal communication, 2015). For firmware versions without (or negligible) cosmetic shift, the background signal consists solely of the instrument-related contributions which may be small. Implications of these instrument-specific variations might be limited for observations within clouds or in the ABL, where backscatter values tend to be large and mostly positive. However, the instrument-related background signal can reach significant values that may dominate any signal differences expected at the top of the ABL. The cosmetic shift in version 1.71 clearly affects observations within the ABL (Sect. 4.2). Note that the cosmetic shift and instrument-related background signal should be carefully evaluated before using noise for quality-control purposes, including absolute calibration and SNR calculations (Sect. 4).

\subsection{Range correction}

For a given concentration of atmospheric scatterers (cloud, aerosol, molecules), the strength of the backscattered signal returned to the ceilometer telescope and detector decreases by the square of the range $r$. Therefore, to relate scattering coefficients at different ranges, the signal $P$ is multiplied by $r^{2}$ at each range gate to obtain the RCS:

$\operatorname{RCS}(r)=P(r) \cdot r^{2}$.

The signal $P$ is determined from the RCS reported by the CL31 by reverting Eq. (5). Vaisala instruments have an option for the range correction to be applied only to the signal in the lower part of the profile up to a set range $r_{\mathrm{H} 2}$, where it is implicitly assumed that most of the data at further ranges consists of noise (setting: "Message profile noise_h2 off"). If no clouds are present in the profile, the raw signal is multiplied by a constant, range-invariant scale factor $k_{\mathrm{H} 2}$ above $r_{\mathrm{H} 2}\left(\mathrm{CL} 31: r_{\mathrm{H} 2}=2400 \mathrm{~m}\right.$ and $k_{\mathrm{H} 2}=r_{\mathrm{H} 2}^{2}=2400^{2}$ ). The partly range-corrected signal reported $\mathrm{RCS}_{\mathrm{H} 2}$ has two segments:

$\mathrm{RCS}_{\mathrm{H} 2}=\left\{\begin{array}{l}P(r) \cdot k_{\mathrm{H} 2}, r>r_{\mathrm{H} 2}, \\ P(r) \cdot r^{2}, r \leq r_{\mathrm{H} 2} .\end{array}\right.$

When clouds are detected, the cloud signal is rangecorrected using Eq. (5) for range gates where cloud is determined to exist. To create a fully range-corrected signal from such observations for the whole vertical profile (according to Eq. (5), i.e. as if run with the setting "Message profile noise_h2 on") in the absence of clouds, the scale factor needs to be reversed and the range correction applied to the observations above $r_{\mathrm{H} 2}$ :

$\mathrm{RCS}=\left\{\begin{array}{l}\operatorname{RCS}_{\mathrm{H} 2}(r) \cdot k_{\mathrm{H} 2}^{-1} \cdot r^{2}, r>r_{\mathrm{H} 2}, \\ \operatorname{RCS}_{\mathrm{H} 2}(r), r \leq r_{\mathrm{H} 2} .\end{array}\right.$

Still, this correction may only be applied where no clouds are present. Hence attenuated backscatter observations obtained with the setting "Message profile noise_h2 off" are of limited use (Mariana Adam, Met Office, personal communication, 2014; http://www.ceilinex2015.de). For ceilometers operating with "Message profile noise_h2 on", all firmware applies the range correction throughout the entire profile and no constant scale factor is incorporated in this processing step. Hence it is recommended to operate with this setting turned on.

The range histograms of the range-corrected signal (Fig. 1b, c) illustrate the increase in signal variability with range. After applying the full range correction (Eq. 7) to observations from a CL31 operated with "Message profile noise_h2 off" (rightmost panel in Fig. 1), the variability of the signal is height-invariant above the ABL (Fig. 1a), while the expected increase is found in the range-corrected signal (Fig. 1b, c); i.e. it has the same signature as if it were recorded with the setting switched on.

\subsection{Optical overlap}

The receiver field of view reaches complete optical overlap with the emitted laser beam at a certain distance above the in- 
strument. This overlap depends on instrument design. Overlap correction functions can be applied to partly account for this effect, with dimensionless multiplication factors determined empirically (e.g. Campbell et al., 2002). The overlap correction may either be performed by firmware or during post-processing. Uncertainty remains for observations at the closest range gates (e.g. Vande Hey, 2014; Hervo et al., 2016).

Applying an optical overlap correction $O(r)$ to the signal, yields the overlap-corrected signal:

$P^{\mathrm{OC}}(r)=P(r) \cdot O(r)^{-1}$.

Vaisala ceilometers have a single-lens, coaxial beam setup (Münkel et al., 2009). For the CL31, complete optical overlap is reached at about $70 \mathrm{~m}$ from the instrument (Fig. 5) and an overlap correction is performed by the firmware (i.e. $P(r)=$ $\left.P^{\mathrm{OC}}(r)\right)$. No other commercially available ceilometer offers complete overlap that close to the instrument. Vaisala overlap functions are verified both by ray tracing simulations and laboratory measurements.

\subsection{Near-range correction}

Although Vaisala suggests that the attenuated backscatter profile is reliable down to the first range gate, Sokół et al. (2014) document a distinct local minimum in CL31 attenuated backscatter observations at the fourth range gate persisting throughout their whole observational campaign. As others have found artefacts in CL31 profiles below $70 \mathrm{~m}$ (e.g Martucci et al., 2010; Tsaknakis et al., 2011), these lowest layers are often excluded during processing. As noted, van der Kamp (2008) smoothed out systematic features by strong vertical averaging, but this removes the possibility of identifying any atmospheric features close to the surface. Without correction, these artefacts may cause detection of significant gradients when examining profiles to diagnose mixing heights or top of the ABL. Artefacts in the first $70 \mathrm{~m}$ could be related to the incomplete optical overlap (Sect. 3.3) but are more likely associated with a hardware-related perturbation and a correction introduced by Vaisala to prevent unrealistically high values in the near range when the window is obstructed.

Given the primary function of cloud base height detection, Vaisala CL31 firmware addresses effects causing extremely high backscatter values outside of clouds. Under severe window obstruction (e.g. leaf on window), values in the first range gates can be unrealistically high. A correction is applied to restrict the backscatter profile in the ranges closest to the instrument. At times, this correction introduces extremely small values at ranges $<50 \mathrm{~m}$ that are clearly offset from the observations above this height. In addition to this artefact from the obstruction correction, for some sensors, backscatter values in the range of $50-80 \mathrm{~m}$ are slightly offset by a hardware-related perturbation. Both artefacts from the obstruction correction and hardware-related perturbation

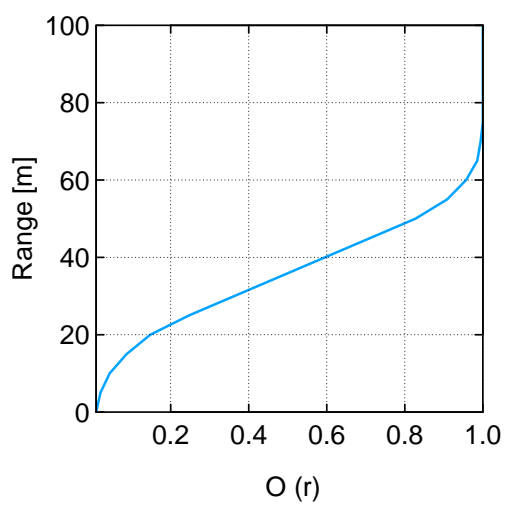

Figure 5. Manufacturer-deduced overlap function of Vaisala CL31 ceilometers using firmware versions 1.71, 1.72, 2.02, or 2.03 (older versions used an overlap function with 5 to $10 \%$ lower overlap values). The function, applied in the lowest range gates above the instrument, is derived from laboratory measurements and field observations under homogeneous atmospheric conditions. During the production process, the applicability of the overlap function is verified for each unit. Due to the stable instrument conditions (e.g. low internal temperature variations), Vaisala expects no systematic variations of the overlap function. The error is stated to be below $10 \%$.

do not impact cloud detection, vertical visibility, or boundary layer structures $(>80 \mathrm{~m})$. It is only for attenuated backscatter closer than $90 \mathrm{~m}$ that these artefacts need to be accounted for. The issues are not firmware specific apart from versions 1.72 and 2.03, in which the artefacts of obstruction correction and hardware-related perturbation have been mostly removed. These near-range artefacts are expected to be consistent in time for data collected with older firmware.

To evaluate the effect of the obstruction correction and hardware-related perturbation, profiles of the range-corrected reported signal in the lowest $90 \mathrm{~m}$ are normalised by the value at $100 \mathrm{~m}(\operatorname{RCS}(n) / \operatorname{RCS}(10)$, with $n=$ range gate; here using LUMO sensors A-D with range resolution of $10 \mathrm{~m}$, Table 2). Selecting daytime profiles (11:00-16:00 UTC, $\mathrm{RCS}<200 \times 10^{-8}$ a.u. for range $<400 \mathrm{~m}$; note no absolute calibration is applied) shows that the normalised profiles have a consistent shape across the four LUMO CL31 sensors (Fig. 6a). The median profile has a small reduction in backscatter at $80 \mathrm{~m}$ (eighth gate), a distinct peak at $50 \mathrm{~m}$ (fifth gate) and rather similar values in the lowest four gates $(<40 \mathrm{~m})$. The artefacts are of smaller magnitude in observations from sensor $B$. The normalised values in the first four range gates have two different regimes: while for most profiles the normalised overlap- and range-corrected signal ranges between 1.0 and 1.2 (Fig. 6b), a small fraction of samples have lower values $(\operatorname{RCS}(2) / \operatorname{RCS}(10)<0.8$; Fig. $6 \mathrm{c})$. This effect is likely explained as an artefact of the obstruction correction while the deviations at 50 and $80 \mathrm{~m}$ are associated with the hardware-related perturbation. The observed range of values provides uncertainty information for the detection of the near-range artefacts; the peak at the fifth range gate 


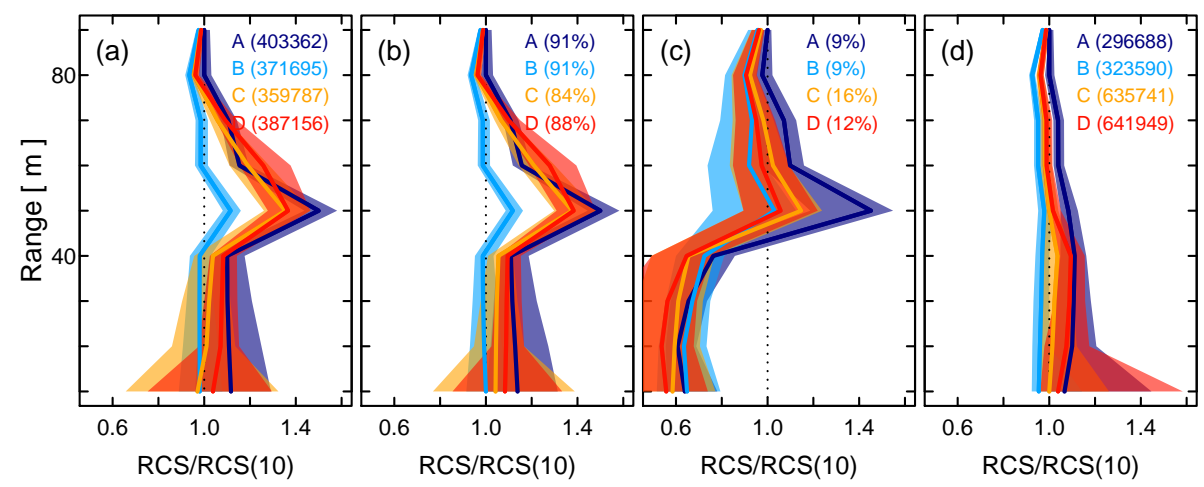

Figure 6. Median range-corrected signal reported $\mathrm{RCS}=P \cdot r^{2}$ of the lowest nine range gates $(10-90 \mathrm{~m})$ normalised by the value at the 10 th range gate for four LUMO sensors (Table 2) with firmware versions (a-c) 1.61 (A, B) or 2.01 (C, D) in 2013 and (d) 1.72 (A, B) or 2.03 (C, D) in 2015-2016, respectively. Statistics calculated for all profiles observed between 11:00 and 16:00 UTC with RCS $<200 \times 10^{-8}$ a. u. in the lowest $400 \mathrm{~m}$ : median (solid line) and interquartile rage (shading). Panels (b) and (c) separate the profiles from panel (a) into (b) profiles with the ratio at the third range gate, i.e. $|\operatorname{RCS}(3) / \operatorname{RCS}(10)|$ exceeding or equal to 0.8 , while (c) shows the profiles with the same ratio less than 0.8 . For $(\mathbf{a}, \mathbf{d})$ the total number of $15 \mathrm{~s}$ profiles selected is indicated by sensor ID (A, B, C, or D) and in (b, c) the percentages of the values from the total number of profiles in panel (a) are given.

indicates an overestimation of about $40-50 \%$, while systematic differences are commonly $<20 \%$ for the remaining range gates below $100 \mathrm{~m}$. For dry and well-mixed conditions, profiles observed with firmware 1.72 or 2.03 (Fig. 6d) indicate that the obstruction correction and hardware-related perturbation might be removed with these updates.

Based on the median climatological profiles (Fig. 6), a near-range correction is proposed to reduce the impact of the obstruction correction and hardware-related perturbation. Only profiles that roughly match the general shape of the climatology are corrected; i.e. if strong vertical gradients in the signal are observed (e.g. descending fog) the near-range correction is inapplicable. However, these near-range artefacts are usually small compared to the physical processes influencing the attenuated backscatter across the profile.

Given that all sensors tested have a distinct peak at a certain range gate (Fig. 6a) this peak is used to indicate whether a correction should be applied. The inverse approach could correct observations with a strong local minimum at the fourth range gate as reported by Sokół et al. (2014). The aim is to apply the near-range correction only to profiles with a pronounced peak value that appears physically unreasonable. First, the range gate with the peak is identified from the climatology (fifth range gate for LUMO sensors). Second, the peak strength is defined as the ratio of the rangecorrected signal reported at this range gate to that reported at the adjacent gates (i.e. fourth and sixth for LUMO sensors). If both these peak-strength indicators of a given profile are at least $25 \%$ as strong as the peak-strength indicators of the climatology profile, the values of this profile in the near range $(<100 \mathrm{~m})$ are divided by the median climatology profile (Fig. 6b). Profiles affected by the obstruction correction, i.e. with clearly offset values in the first four range gates, are treated separately. If the first peak-strength indicator (i.e. the one below the peak) is at least $50 \%$ as strong as the respective indicator of the climatology of this regime (Fig. 6c) and the value at the range gate of the peak is greater than the values in the two range gates above, the respective median climatology profile is used for the correction (Fig. 6c).

Correction functions can help to reduce the processing artefact due to the obstruction correction and the hardwarerelated offset as demonstrated for several case studies (Fig. 7; LUMO ceilometers A-D, see Table 2). Observations taken with firmware versions $<1.72$ (for systems running with engine board plus receiver combination CLE311 + CLR311) or $<2.03$ (CLE321 + CLR321) have clear near-range effects (Fig. 6a-c) evident in the data recorded (Fig. 7i, iii, v). Two examples are clearly affected by the obstruction correction (Fig. 7iii, ceilometers $C$ and D) with values in the lowest four range gates negatively offset. After the near-range correction is applied, this effect is reduced and the artificial peaks at the fifth range gate are mostly removed (Fig. 7ii, iv, vi). Although some residual effects may remain, extreme vertical gradients encountered within the lowest $100 \mathrm{~m}$ of the original range-corrected signal reported by the CL31 ceilometers are mostly removed.

Vaisala introduced a correction for the near-range artefacts that proves efficient in dry conditions (Fig. 6d); however, if attenuation is increased due to hygroscopic growth, the peak at the fifth range gate is still evident in the normalised RCS profile (Fig. 7vii). Applying the near-range correction proposed for observations from earlier firmware version (as used for Fig. 7ii, iv, vi), the artefacts could still be removed (Fig. 7viii, ceilometers A and B), but it could also result in an overcorrection (Fig. 7viii, ceilometers C and D). Note that this approach can only be tested on sensors for which a historic dataset of measurements with older firmware versions is available to calculate the respective correction 

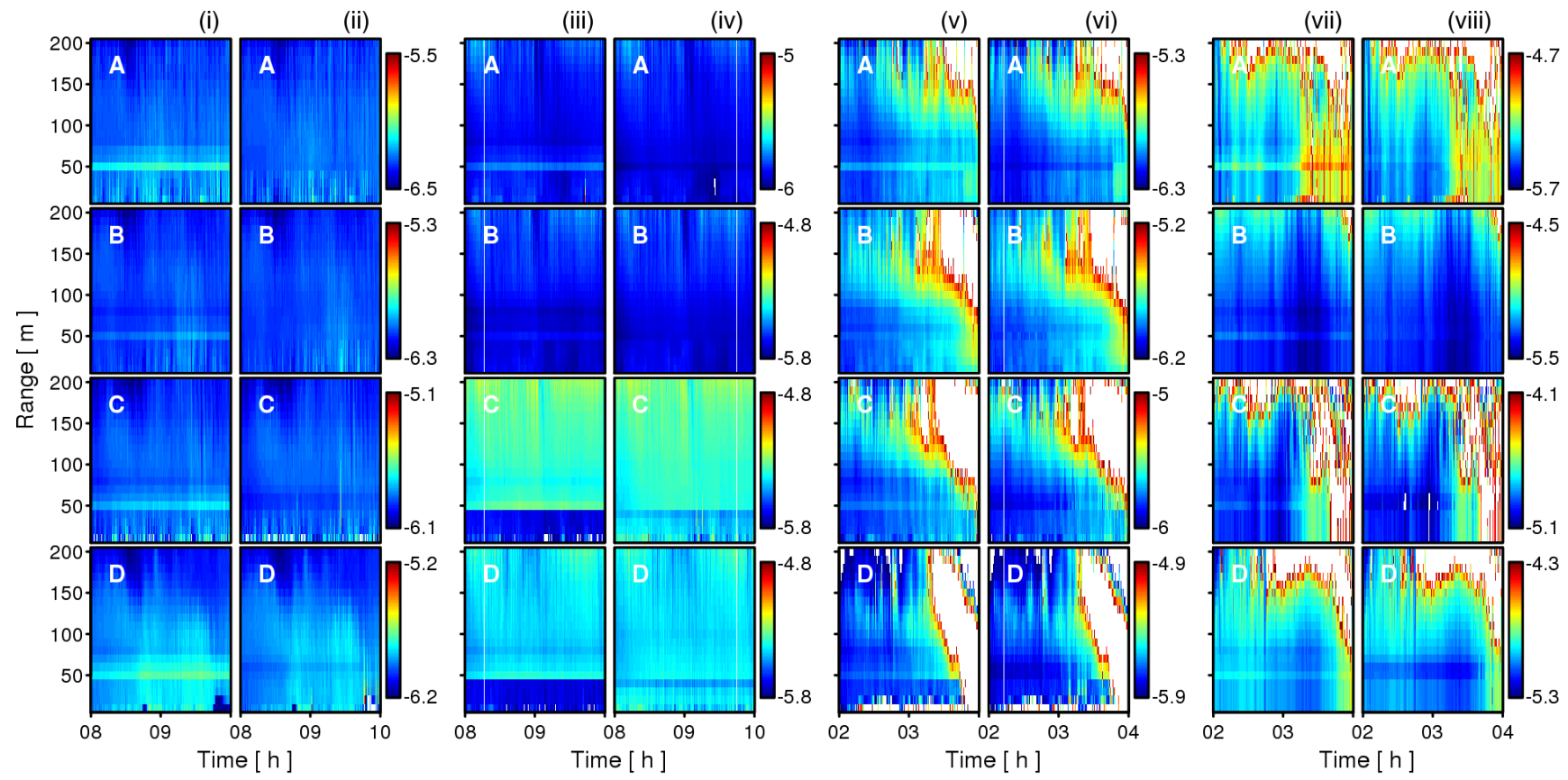

Figure 7. Observations from four Vaisala CL31 ceilometers from the LUMO network (Table 2) over the first $200 \mathrm{~m}$ range: (i, iii, v, vii) logarithm of the range-corrected signal reported RCS (a. u.); (ii, iv, vi, viii) as in (i, iii, v, vii) but after application of correction for near-range artefacts associated with the obstruction correction and a hardware-related perturbation (see Fig. 6). Sensors were operating with firmware 1.61 (A, B) and 2.01 (C, D) on (i, ii) 10 January 2014, (iii, iv) 15 January 2014, (v, vi) 6 January 2013, and firmware 1.72 and 2.03 on (vii, viii) 13 March 2016. White areas indicate values outside of the range of values selected (see colour legends). Note that data are not absolutely calibrated.

profiles (Fig. 6). Given that the near-range correction introduced by Vaisala in versions 1.72 and 2.03 is not sufficient in moist conditions with gradients along the profile (Fig. 7vii), it was proposed to Vaisala to remove their correction again so that the near-range correction can be applied during postprocessing.

\section{Absolute backscatter and quality assurance}

\subsection{Absolute calibration}

The range-corrected attenuated backscatter $\beta \cdot r^{2}$ describes the range-corrected and background-corrected signal calibrated by the lidar constant $C$ :

$\beta \cdot r^{2}=\hat{P} \cdot C^{-1} \cdot r^{2}$.

The lidar constant $C$ is a function of the range-independent parameters of the lidar equation, including the speed of light, area of the receiver telescope, temporal length of a laser pulse, a system efficiency term, and mean laser power per pulse (Weitkamp, 2005). It depends on instrument receiver design and its laser. When the instrument is new, system efficiency and laser power are high. At this stage, the lidar constant for internal calibration is determined by a factory-based test $\left(C=C_{\text {factory }}\right)$. Even with regular cleaning and maintenance, the performance of a sensor changes over time (e.g. aging of the laser, changes in window transmissivity). To account for such possible variations in laser output and detector capability over time, the ceilometer firmware monitors the laser output energy and determines a relative calibrationcorrection factor $c_{\text {monitor }}(t)$, which is a time-specific lidar constant applied internally:

$C_{\text {internal }}(t)=C_{\text {factory }} \cdot c_{\text {monitor }}(t)$.

Over time, this internal checking of the instrument performance potentially provides a continuous relative calibration. Given that the signal output by the ceilometer already has the internal calibration applied, it is labelled "attenuated backscatter" by the manufacturer. However, it has been shown that the internal calibration factor $C_{\text {internal }}$ does not always fully represent the actual lidar constant (e.g. O'Connor et al., 2004) and that an absolute calibration should be performed in sufficiently known atmospheric conditions. Given the background noise of the CL31 sensors dominates over the molecular backscatter (Sect. 2), the stratocumulus cloud technique (O'Connor et al., 2004) is the most appropriate calibration technique for the Vaisala sensors. This agrees with the findings of the TOPROF community (Maxime Hervo, Meteo Swiss, personal communication, 2015). The stratocumulus cloud technique relates the observed signal to the known integrated attenuated backscatter coefficient associated with thick liquid clouds. This absolute calibration tech- 
nique is applied externally, i.e. as part of the post-processing:

$\beta \cdot r^{2}=\left(P_{\text {internal }} \cdot C_{\text {internal }}(t)^{-1}\right) \cdot c_{\text {absolute }}(t)^{-1} \cdot r^{2}$.

The absolute calibration coefficient $c_{\text {absolute }}(t)$ may be constant in time $c_{\text {absolute }}(t)=c_{\text {absolute }}$ (Hopkin et al., 2016). A laser at the CL31 operating wavelength $(\approx 905 \mathrm{~nm})$ is sensitive to absorption of water vapour in the atmosphere, which can have implications for the absolute calibration (Markowicz et al., 2008; Wiegner and Gasteiger, 2015). As evaluation of absolute calibration techniques is beyond the scope of this study, for simplicity the impact of this external calibration is neglected (i.e. $c_{\text {absolute }}(t)=1$ ).

\subsection{Signal strength and noise}

Given that noise is a critical component of the attenuated backscatter recorded, data with values below a certain SNR are unlikely to contain sufficient information about the state of the atmosphere. Where high-resolution observations are obtained, rolling spatial (along-range) and temporal averaging increases the signal contribution relative to the noise. For every range gate $r$ and time step $t$, the smoothed attenuated backscatter is the average over a temporal window of fixed size $2 w_{t}+1$ (with $w_{t}$ time steps) and a range window of fixed size $2 w_{r}+1$ :

$$
\begin{array}{r}
\beta_{\text {smooth }}(t, r)=\left(2 w_{t}+1\right)^{-1} \cdot\left(2 w_{r}+1\right)^{-1} \\
\sum_{k=r-w_{r}}^{k=r+w_{r}} \sum_{h=t-w_{t}}^{h=t+w_{t}} \beta(h, k) .
\end{array}
$$

Optimal window length depends on hardware characteristics (i.e. noise levels), resolution settings for raw data acquisition, and the application. Here, window lengths combining to a total of about 1000 have been found suitable to prepare data for the detection of mixing height with a relatively larger temporal averaging window (i.e. $w_{t}=50$; $w_{r}=5$, which equals $25.25 \mathrm{~min}$ and $110 \mathrm{~m}$ for the LUMO sensors; see Table 2) as features of the ABL structure show more variability in the vertical than over time. Such large window sizes can significantly improve the SNR, i.e. signal strength compared to average background noise, while smallscale variability is mostly preserved due to the moving average. If block averaging is applied, shorter averaging windows might be more appropriate. For example, Sokół et al. (2014) find a 5 min window suitable for block averaging attenuated backscatter of a CL31 prior to mixing height analysis in the morning transition period as boundary layer dynamics may vary at $30-60 \mathrm{~min}$ timescales. To significantly increase SNR, Stachlewska et al. (2012) use Gaussian smoothing (Jenoptik CHM15K ceilometer) with linearly increasing range window widths; however, this is can result in extensive computing time. BLview (Vaisala's boundary layer detection software, e.g. used by Tang et al., 2016) has range-variant smoothing windows.
The quality of range-corrected attenuated backscatter can be evaluated by comparison to the noise floor. The latter represents variations associated with electronic and optical noise and noise introduced by the solar background light. If no high cirrus clouds are present, it is assumed the signal from the very highest range gates contains only noise (i.e. atmospheric signal contribution is negligible). In this case, the noise floor $F$ can be defined as the mean $\bar{\beta}$ plus standard deviation $\sigma_{\beta}$ of the attenuated backscatter $\beta$ (i.e. before range correction) across a certain number of gates from the top of the profile. Statistics are applied across these gates at the top of the profile and moving temporal windows (as in Eq. 12):

$$
F(t)=\bar{\beta}(t)+\sigma_{\beta}(t) .
$$

Here, the highest $300 \mathrm{~m}$ of the profile $(N=30$ at $10 \mathrm{~m}$ resolution) are used to determine the noise floor to ensure sufficient representation of the range variability. Similar results are obtained with slightly more range gates. The discontinuity and increased noise levels around $7000 \mathrm{~m}$ (Sect. 3.1) make it inadvisable to include more than $600 \mathrm{~m}$ to calculate the noise floor. The mean $\bar{\beta}$ across the top range gates is usually small and fluctuates around 0 . However, if the background correction (Sect. 3.1) is not performed it can have a slight offset from 0 and even a diurnal pattern for data acquired with firmware version 1.71, which performs the cosmetic shift based on the dynamic zero-bias level (Sect. 2). Calculated from the entirely background-corrected signal or attenuated backscatter (see Eq. 1-4), the noise floor $F$ is nearly equal to the standard deviation $\sigma_{\beta}$ across the top range gates.

To ensure that profiles used for the calculation of $F$ do not contain any cirrus clouds, which can provide significant backscatter even at the furthest ranges of the profile, the "relative variance" $\mathrm{RV}(t, r)$ (or coefficient of variation) is used to mask cloud observations (Manninen et al., 2016). For each time $t$ and range $r$ (at the top of the profile), the relative variance is the ratio of the standard deviation $\sigma_{\beta}(t, r)$ to the mean $\bar{\beta}(t, r)$, with statistics applied over moving windows (as in Eq. 12), along range and time (here, $w_{r}=w_{t}=3$ were used):

$\mathrm{RV}(t, r)=\left(\frac{\sigma_{\beta}(t, r)}{\bar{\beta}(t, r)}\right)^{2}$.

If $\mathrm{RV}(t, r)$ is sufficiently small, then the backscatter is interpreted as a true signal backscattered by atmospheric constituents of interest (e.g. cirrus clouds). Such backscatter values should not be incorporated into the calculation of the noise floor (Eq. 13). Rather, $F$ should be estimated for observations when $\mathrm{RV}$ exceeds a threshold $T_{1}, \beta=\beta\left(\mathrm{RV}>T_{1}\right)$. A threshold of $T_{1}=1$ indicates that the variability exceeds the mean signal and can be used to mask strong backscatter from clouds. Times with a small number of gates (e.g. layer $<100 \mathrm{~m}$ ) available for calculation of the noise floor (i.e. when many of the top range gates have cirrus) can be interpolated linearly in time. A day with cirrus in the top gates (Fig. 8) illustrates how the threshold $T_{1}$ can be applied to 


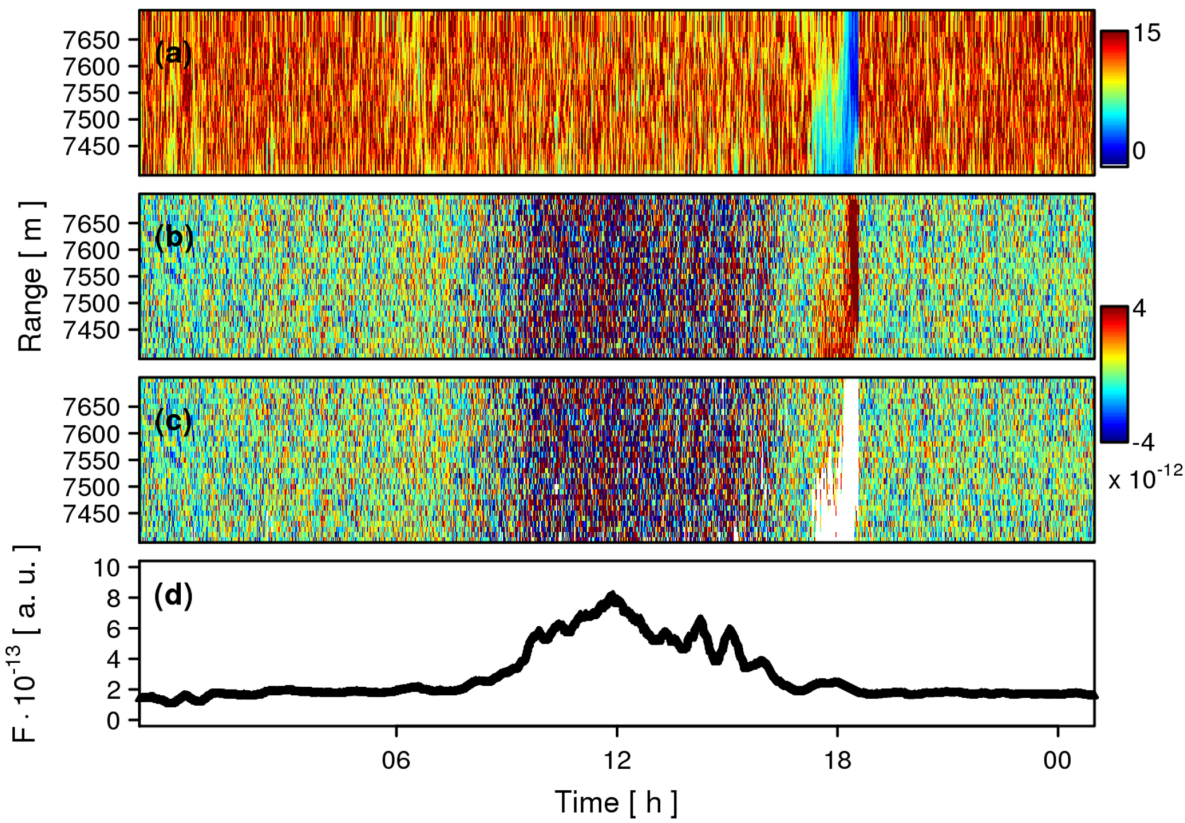

Figure 8. Observations from Vaisala CL31 sensor D (Table 2) at top range gates (7410-7700 m) with cirrus during the early evening on 1 February 2013: (a) relative variance RV (Eq. 14); (b) background-corrected signal $\hat{P}$; (c) same as (b) but only including observations with $\mathrm{RV}>1$; and (d) time series of the noise floor $F$ (Eq. 13) based on the cleaned signal shown in (c) with missing values interpolated linearly.

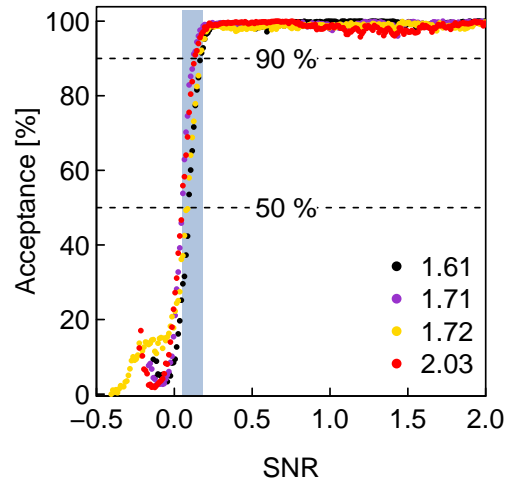

Figure 9. Acceptance (\%) based on Welch's $t$ test with a $p$ value of 0.01 of smoothed, not range-corrected, attenuated backscatter (Eq. 12) to be significantly higher than the noise floor (Eq. 13), binned by the corresponding signal-to-noise ratio (SNR, Eq. 15) for four selected cases ( $24 \mathrm{~h}$ each; range 50-3000 m shown for simplicity) of observations taken with different firmware versions (see legend). The shaded area marks the SNR region corresponding to acceptance levels of $50-90 \%$.

convert the RV field (Fig. 8a) into a mask to remove the cirrus signal from the attenuated backscatter (Fig. 8b). Based on the attenuated backscatter with clouds masked out (Fig. 8c), the noise floor $F$ is calculated over the course of the day (Fig. 8d) and the area missing due to the presence of cirrus is interpolated linearly over the time period where the attenuated backscatter has been masked out.
The SNR is calculated from smoothed, non-rangecorrected attenuated backscatter (Eq. 12) and the noise floor $F$ :

$\operatorname{SNR}(t, r)=\frac{\beta_{\text {smooth }}(t, r)}{F(t)}$.

Note that in clean air with low aerosol content the dominant scattering is molecular, which is below the sensitivity of the CL31 ceilometer (Sect. 2). Furthermore, thick liquid clouds have the ability to (almost) fully attenuate the ceilometer signal so that any returns from above such a cloud layer (or even within it) correspond to noise rather than to atmospheric scattering from particles or molecules. Hence, at certain heights the information content of the signal may be limited. To evaluate where the signal contribution is clearly distinguishable from the noise, Welch's $t$ test (Welch, 1947) is performed comparing the distributions of $\beta_{\text {smooth }}$ and $F$, assuming they are both normally distributed. As $\beta_{\text {smooth }}$ was found to deviate from normality below a range of about $500 \mathrm{~m}$, the $t$ test was only performed for higher ranges. A $p$ value $<0.01$ was chosen to accept that $\beta_{\text {smooth }}$ significantly exceeds the noise floor at the respective time step and range gate. The acceptance level calculated for each SNR bin (Fig. 9) reveals a clear divide between observations with high information content and those with a magnitude comparable to the noise floor (or lower). For the LUMO sensors (Table 2) acceptance levels of 50-90\% correspond to SNR values of $0.05-0.20$, which indicates the range of threshold values $\left(T_{2}\right)$ that can be selected depending on whether a more relaxed or conservative filtering is desired. These low values can be explained 


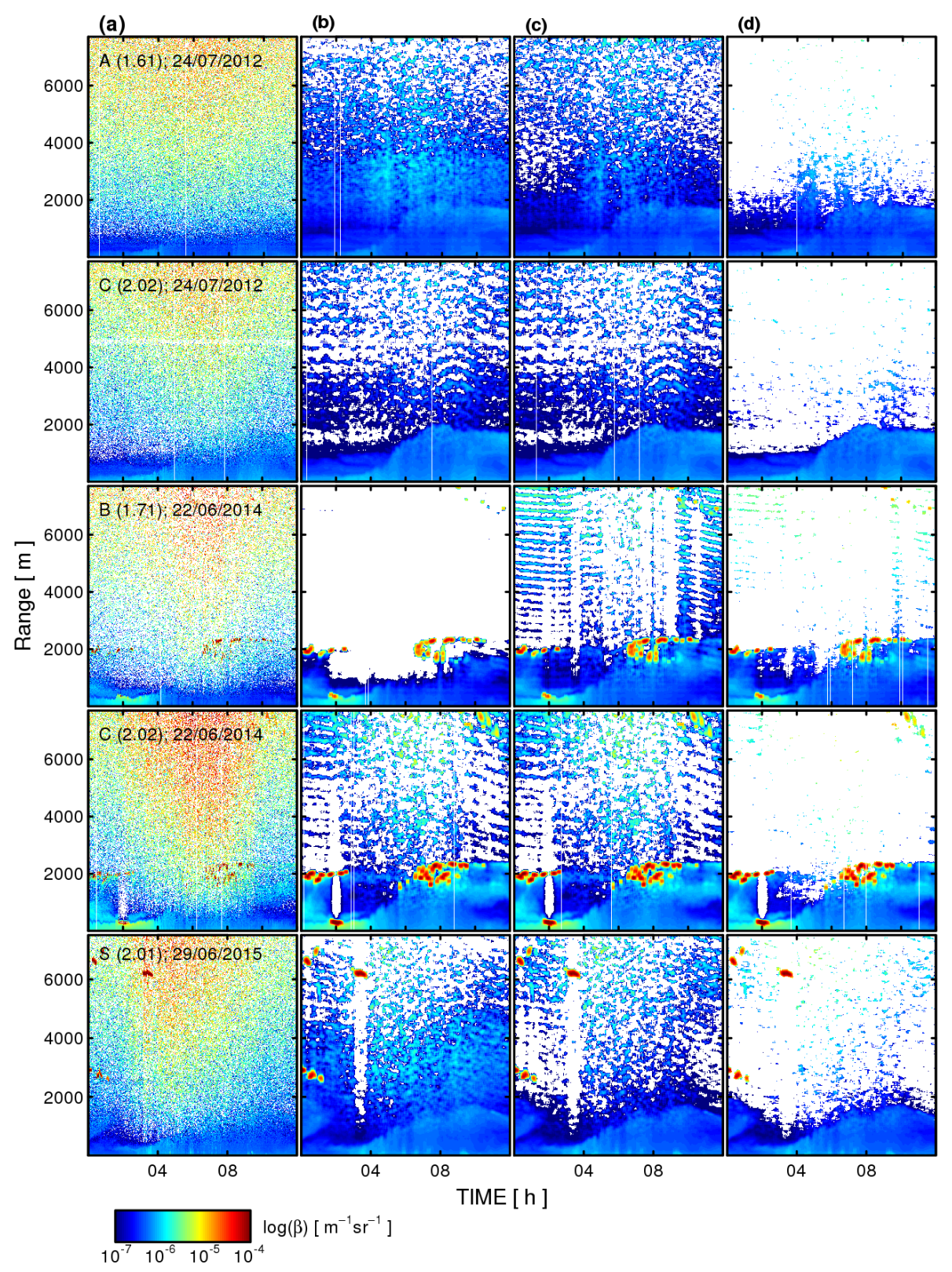

Figure 10. CL31 observations on 24 July 2012 (rows 1 and 2), 22 June 2014 (rows 3 and 4), and 29 June 2016 (row 5) from four sensors with firmware version in brackets: A (1.61), B (1.71), C (2.02), and S (2.01); see Table 2. (a) Range-corrected attenuated backscatter $\beta \cdot r^{2}$ at $15 \mathrm{~s}$ resolution (rows 1-4) and $30 \mathrm{~s}$ (row 5) as reported; (b) as in (a) with running average ( $25 \mathrm{~min}, \sim 100 \mathrm{~m})$ applied (Eq. 12); (c) as in (b) but including correction of instrument-related background signal and potential cosmetic shift (see Sect. 3.1); and (d) as in (c) but filtered for SNR $>T_{2}$, with $T_{2}=0.18$ (see discussion on Fig. 9). Note: for simplicity the absolute calibration constant is here assumed to be $c_{\text {absolute }}=1$ (Sect. 4.1) for all sensors. This is not necessarily expected to be a correct assumption in reality but applied to show the impact of corrections on the final product, i.e. the attenuated backscatter.

by the fact that most observations with no significant signal contribution become or remain negative after smoothing (Eq. 12) has been applied. If attenuated backscatter profiles are used for the detection of layers in the ABL, it is recommended to include data with $\beta_{\text {smooth }}$ (SNR $>T_{2}$ ) at a given point in time and range $r$ but also if the threshold is exceeded at a certain range below $(r-\Delta r)$. This is to ensure gradients can be calculated in the entrainment zone even if the clear air above the ABL is associated with very low SNR values. The appropriate range distance $\Delta r$ depends on the degree of smoothing applied and the calculation of the vertical gradient for layer detection.

The impact of averaging, background correction, and noise filtering on observations taken by different sensors and 
firmware versions is illustrated based on three case study days (Fig. 10): 24 July 2012 with clear-sky conditions comparing sensor A running with firmware version 1.61 (row 1) and to sensor C with firmware 2.02 (row 2), 22 June 2012 with some boundary layer clouds present comparing sensor B with 1.71 (row 3) and sensor C with firmware 2.02 (row 4), and 29 June 2015 with a few isolated medium- and high-level clouds showing observations from sensor $\mathrm{S}$ with 2.01 (row 5). The range-corrected attenuated backscatter reported (Fig. 10a) is quite noisy in all sensor observations and the evolution of the ABL is difficult to discern. When the moving average is applied (Fig. 10b), the signal contribution clearly increases so that aerosol layers can be identified visually. However, the contrast between ABL and the clear air above varies greatly with sensor and firmware version. While the ABL reveals distinct attenuated backscatter signatures for data from sensor $\mathrm{C}$ with firmware 2.02 (rows 2 and 4 ), the values in the free troposphere are elevated for sensors A (row 1) and S (row 5). This is explained by the different profiles of background signal inherent in these observations (Fig. 3a): sensor $\mathrm{C}$ has a small and slightly negative background signal which barely affects observations above the ABL, while both sensor A (firmware 1.61) and sensor S (2.01) have a positive background signal leading to an overestimation of signal below about $5000 \mathrm{~m}$. Even more severe is the impact of the cosmetic shift inherent in observations from sensor B (1.71; row 3), which reduces the signal significantly even within the ABL. For the example shown, average values become negative below the boundary layer clouds so that no mixing height detection algorithm would be able to derive relevant statistics.

The described artefacts can mostly be accounted for by the proposed background correction (Eq. 1-4; Fig. 10c). While it can help to improve the contrast at the boundary layer top for sensors A (row 1) and S (row 5), it can revert the cosmetic shift in data from sensor B (row 3). In the latter case, the background correction can increase data availability. It should be noted that the systematic ripple effect (sensors B and C; see Sect. 3.1) becomes apparent after the background correction. Although the ripple is somewhat coherent and not truly random, affected areas above the ABL can still be successfully masked by the SNR filter (Fig. 10d). For all sensors, the statistical threshold helps to distinguish data with significant information content (compare Fig. 10c, d) so that quality can be assured for later applications (e.g. mixing height detection). Still, some significant noise may remain near the ABL top for the older generation of hardware running with firmware 1.xx (row 1 and 3 ). It can be concluded that data quality of sensors of the recent hardware generation, i.e. those operating firmware version 2.xx (here sensors $\mathrm{C}$ and $\mathrm{S}$ ) are clearly superior to older generations (sensors $\mathrm{A}$ and $\mathrm{B})$.

\section{Summary}

Ceilometers are valuable instruments with which to study not only clouds but also the ABL and elevated layers of aerosols. Vaisala CL31 sensors provide good-quality attenuated backscatter. While their cloud base height product might be readily useful, to understand the profiles of attenuated backscatter the user needs to be aware of the instrument model's specific hardware and firmware. The following sections summarise aspects useful to consider in the postprocessing of CL31 ceilometer attenuated backscatter profiles.

By taking into account these instrument-specific aspects of the CL31 profile observations, data quality and availability can be improved. If data are collected according to best practice, as recommended (Sect. 5.3), issues are being corrected for in the post-processing (e.g. applying the proposed methods) and sensors are carefully calibrated, then the attenuated backscatter observations might prove useful for NWP model verification and evaluation, and potentially even for data assimilation.

\subsection{Instrument-specific characteristics and issues}

Initial internal averaging of the sampled ceilometer signal is applied over selected time intervals that depend on the range and the user-defined reporting interval for firmware versions $<1.72,2.01$, and 2.02. Data acquired with firmware 1.72 or 2.03 are more consistent than earlier versions because the whole profile (at all range gates) is treated equally with an internal averaging interval of $30 \mathrm{~s}$.

If the user-defined reporting interval is shorter than $30 \mathrm{~s}$, consecutive profiles partly overlap in time and are hence not completely independent.

When averaging several profiles, a discontinuity is evident at around both 4940 and $7000 \mathrm{~m}$ for all sensors and firmware versions. These regions of increased noise are introduced by the data storage procedure of the firmware, which slightly changes its operating mode after a certain number of gates have been collected. Care should be taken when looking at gradients or statistics near these ranges.

Depending on firmware version, a "cosmetic shift" is applied to the attenuated backscatter profiles. This shift should be reversed before using any part of the profile for analysis. Of the firmware tested, the cosmetic shift appears to be negligible for all versions except for 1.71, in which a strong negative shift is applied to the observations.

In addition, a range-dependent, instrument-related background signal is inherent in the signal reported, altering the profiles systematically. The background signal values (instrument-related background signal plus potential cosmetic shift) tend to be either predominantly positive or predominantly negative in ranges below $6000 \mathrm{~m}$ and to switch sign between about 6000 and $7000 \mathrm{~m}$. 
Both the range-dependent instrument-related background signal and the cosmetic shift applied may cause issues for studying the ABL because signal differences expected at the ABL top may be obliterated or the signal reduced too strongly for successful mixing height detection.

Molecular scattering at the instrument wavelength is very weak, typically below the sensitivity of the instrument.

The CL31 measurement design accounts for temporal variations in solar radiation by introducing a variable zerobias level so that the atmospheric background signal is inherently accounted for in the signal reported. However, solar radiation still contributes to the random noise.

In the absence of clouds, rain, or elevated aerosol layers, the recorded signal includes the instrument-related background signal plus potential cosmetic shift and noise associated with both the instrument (electronics and optics) and the solar background radiation. Instrument-related background signal and cosmetic shift should be carefully evaluated before using noise for quality-control purposes.

For some instruments, a "ripple" effect is detected that superimposes a wave-type structure over the random noise. For the sensors evaluated, this was found in two generations of the engine board plus receiver (CLE311+CLR311 and CLE321 + CLR321), but only for transmitter type CLT321. Temporal rolling averages may enhance this ripple effect at short timescales usually used for smoothing raw attenuated backscatter observations (i.e. minutes to hours). Further investigation indicates that the ripple shows some response to the level of attenuation in the ABL.

Vaisala instruments have a setting ("Message profile noise_h2 off") that restricts the range correction to the signal in the lower part of the profile up to a set critical range. It is implicitly assumed that most data at ranges beyond this critical range contain only noise. If no clouds are present in the profile, then the signal is simply multiplied by a constant, range-invariant scale factor. Where clouds are detected, the signal is actually range-corrected as usual, but only for range gates where cloud is determined to exist.

Several artefacts may be found in the lowest range gates close to the instrument. The co-axial beam design of the CL31 ceilometer allows complete overlap to be reached at $70 \mathrm{~m}$. Below this range, an overlap correction is applied internally by the sensor.

In addition to the overlap correction, Vaisala applies another correction to observations from the first few range gates to avoid exceptionally high readings when the ceilometer's view is obstructed (e.g. a leaf on the window). At times, this obstruction correction introduces extremely small values at ranges $<50 \mathrm{~m}$ that appear unrealistically offset from the observations above this height. Attenuated backscatter values may also be slightly offset in the range of 50-80 m which can be explained by a hardware-related perturbation.

Although CL31 output is labelled as attenuated, rangecorrected backscatter, the absolute calibration might not be accurate enough for use in meteorological research. The stra- tocumulus or liquid cloud calibration (O'Connor et al., 2004) can be used to determine the instrument-specific lidar constant based on external properties. This allows absolute calibration to be performed during post-processing. Data gathered with instruments that cause a strong electronic background signal and/or with firmware that applies the cosmetic shift (version 1.71) should be corrected for these effects before the calibration is applied. Note that absolute calibration is included for completeness but is not addressed here.

\subsection{Proposed corrections}

To create a fully range-corrected signal from data gathered with the setting "Message profile noise_h2 off" for the whole vertical profile (as if the setting "Message profile noise_2 on" had been used) in the absence of clouds, the scale factor needs to be reversed and range correction applied to the observations above the critical range.

A climatology of night-time profiles can be used to determine the background correction that is required to account for the instrument-related background signal and potential cosmetic shift. A comparison with termination hood measurements proves the nocturnal climatology accurately describes the background signal. Thus, the two can be considered equivalent and the background correction can be determined through either termination hood reference measurements (e.g. if profile observations are not available for a long time) or the climatology approach (e.g. if historical data are analysed or ceilometer site access is difficult). No reliable information can be derived from the climatology technique below about $2400 \mathrm{~m}$ given the presence of the ABL. However, termination hood profiles show the magnitude of the instrument-related background signal below this range is rather small after range correction so the profile can be assumed as range invariant in this region.

The cosmetic shift has temporal variation through the day, indicating that an influence of the atmospheric background is retained during internal processing. This effect can be accounted for in the background correction by including an offset based on average observations in the top range gates.

The artefacts related to obstruction correction and hardware-related perturbation are mostly accounted for in versions 1.72 and 2.03 , but small effects remain under situations with considerable attenuated backscatter. Hence, removal of this correction in the next firmware update to allow for consistent corrections to be applied during postprocessing was recommended to Vaisala. Data from earlier versions (and probably later versions) need to be corrected during post-processing if observations from the near range are to be analysed; a correction procedure has been proposed based on climatological statistics of well-mixed atmospheric profiles. 


\subsection{Quality assurance}

As the noise in the background-corrected signal is independent of range, it can be determined using the top-most range gates in the profile where the contribution of real atmospheric scattering is negligible in the absence of high cirrus clouds. The noise floor, taken as the mean plus standard deviation of the background-corrected signal (before range correction is applied), is calculated across moving time windows over those top range gates with the mean generally negligible after background correction. Regions containing significant aerosol or cloud should be excluded. They are efficiently masked based on the relative variance.

To increase the SNR, a moving average is calculated for the non-range-corrected attenuated backscatter across set windows in range and time. The relation of these smoothed statistics and the noise floor defines the SNR which may be used to mask observations where the noise exceeds the actual information content of atmospheric signal. A suitable SNR threshold to distinguish the signal from the noise region is estimated based on Welch's $t$ test.

Data quality and SNR of sensors running with engine board CLE321, receiver CLR321, and firmware version 2.xx are superior to those of the old generation (CLE311 + CLR311; 1.xx).

In response to results presented here and discussions within the TOPROF community, Vaisala released two recent firmware versions: 1.72 for sensors running with older generation hardware (engine board CLE311 and receiver CLR311) and 2.03 for sensors running with newer-generation hardware (CLE321 + CLR321). Data collected with these two firmware versions are more consistent and show great improvement in the attenuated backscatter profiles when compared to the data from older firmware versions. Additional suggestions are communicated to the manufacturer to allow for correction of the near-range artefacts during postprocessing rather than performing it online.

\subsection{Concluding recommendations}

Assuming the sensors evaluated in this study are representative of CL31 ceilometers in general, the following recommendations are made for the operation of Vaisala CL31.

i. Operate with the setting "Message profile noise_h2 on".

ii. A reporting interval (temporal resolution) of at least $15 \mathrm{~s}$ is recommended (despite down to $2 \mathrm{~s}$ being possible).

iii. It is advised to operate sensors with engine board CLE321 + receiver CLR321 and firmware version 2.03 (or later).

iv. If only older hardware (CLE311 + CLR311) is available, firmware version 1.72 (or later) should be used. v. The instrument-related background signal should be carefully evaluated for all sensors and firmware versions. This can be achieved based on night-time climatology statistics or termination hood measurements. Correction of the range-dependent background signal may improve the contrast between the $\mathrm{ABL}$ and the clearer air above.

vi. For data gathered with firmware 1.71 , the cosmetic shift can be corrected based on a combination of background signal profile estimates and average attenuated backscatter across the profile's top range gates in the absence of cirrus clouds.

vii. If information close to the sensor $(<100 \mathrm{~m})$ is of interest, near-range artefacts should be corrected in historical data collected with firmware versions $1.54,1.61$, $1.71,2.01$, or 2.02 . This correction might generally not be necessary for data gathered with firmware 1.72 or 2.03; however, it was found to yield some improvement under moist conditions.

viii. Given the impact of both hardware and firmware on attenuated backscatter profiles from CL31 ceilometers, any publication of such data should clearly state relevant details on hardware generation and firmware versions used, if any changes to the setup were made during the measurement period analysed, and post-processing undertaken.

\section{Data availability}

Data of Vaisala CL31 ceilometers used for this study can be accessed from the different sources:

- Data from the LUMO network can be requested online (Grimmond, 2016).

- Data from the Meteo France ceilometer at the SIRTA site can be downloaded from SIRTA (2016), using the "Download tool" menu, selecting "search by instrument", "backscatter LIDAR" category and finally "Ceilometer CL31".

- Met Office data are available from the Centre for Environmental Data Analysis (Met Office, 2015). 
Appendix A: Notation.

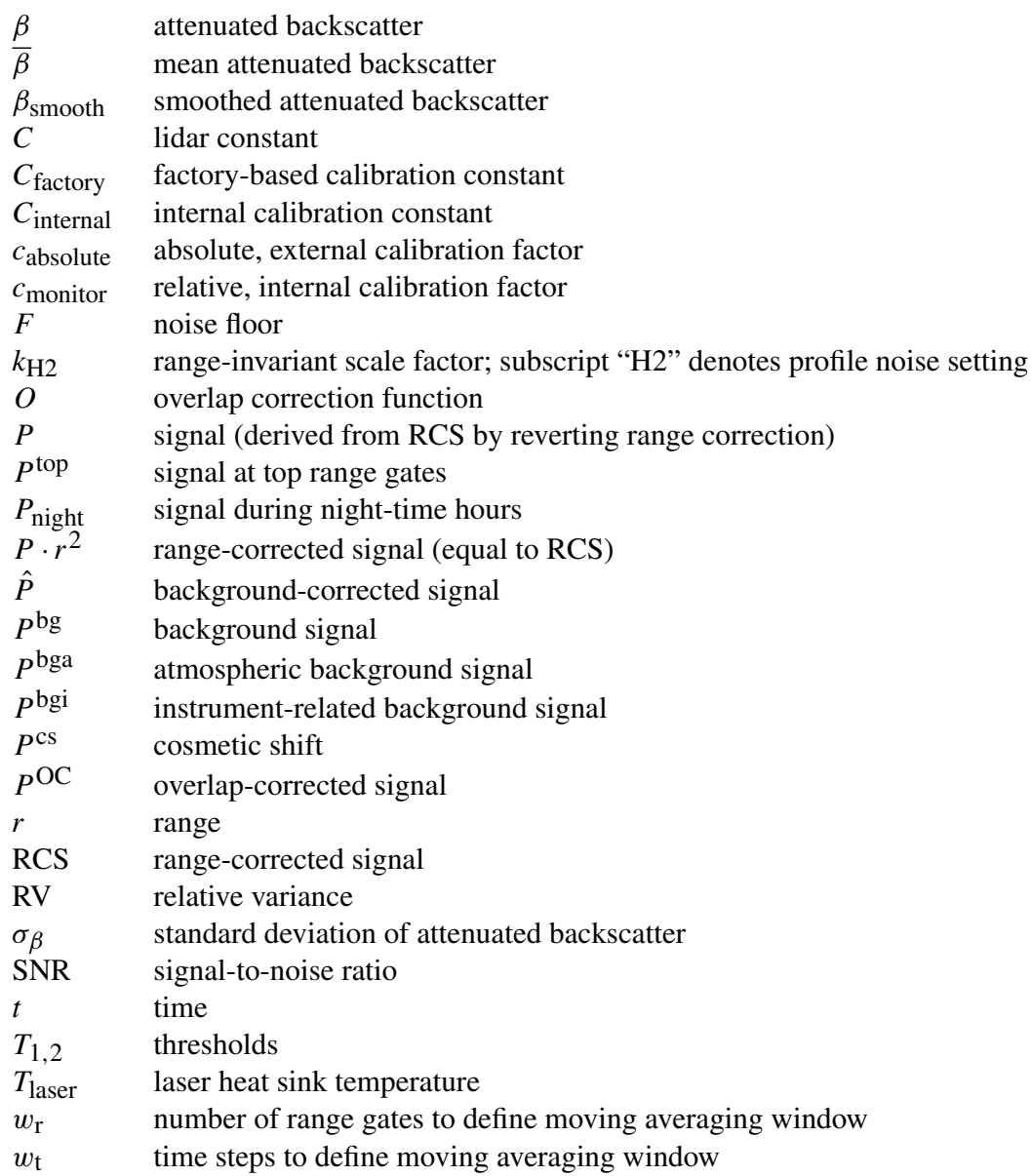


Author contributions. Simone Kotthaus is involved in maintaining the LUMO measurement network, performed all analysis, developed correction procedures, and wrote the main parts of the manuscript. Ewan O'Connor was involved in the development of the background correction, the calculation of SNR, and discussion on range correction and provided useful comments to the manuscript. Christoph Münkel provided information on sensor specifics and internal processing procedures, wrote parts of the manuscript, and provided the TOPROF firmware versions tested in this study. Cristina Charlton-Perez provided CL31 observations from the Met Office sensor, contributed to writing the manuscript, and was involved in discussions on sensor specifics, background correction, range correction, and SNR calculations. Martial Haeffelin provided CL31 data from SIRTA, was involved in discussions on background correction, near-range correction, SNR calculation, and terminology, and provided useful comments to the manuscript. Andrew M. Gabey developed the approach for calculating an appropriate SNR threshold. C. Sue B. Grimmond provided CL31 measurements from the LUMO measurement network, was involved in discussions on instrument specifics and all data processing aspects, and provided useful comments to the manuscript.

Acknowledgements. This study was funded by H2020 URBANFLUXES, NERC ClearfLo (H003231/1), NERC Airpro (NE/N00700X/1), NERC//Belmont TRUC (NE/L008971/1 G8MUREFU3FP-2201-075), European Cooperation in Science and Technology (COST) action "TOPROF": ES1303, King's College London, and University of Reading. We thank KCL Directorate of Estates and Facilities, ERG/LAQN, and RGS/IBG for providing sites and other support and the many staff and students at University of Reading and KCL who contributed to data collection. Met Office, Meteo France, and the SIRTA observatory are kindly acknowledged for providing observations. We would like to acknowledge the useful discussions within the TOPROF community (especially with Mariana Adam, Met Office; Frank Wagner, DWD; and Maxime Hervo, Meteo Swiss). We thank all anonymous reviewers for their comments and helpful suggestions.

Edited by: A. Sayer

Reviewed by: four anonymous referees

\section{References}

Bromwich, D. H., Nicolas, J. P., Hines, K. M., Kay, J. E., Key, E. L., Lazzara, M. A., Lubin, D., McFarquhar, G. M., Gorodetskaya, I. V., Grosvenor, D. P., Lachlan-Cope, T., and van Lipzig, N. P. M.: Tropospheric clouds in Antarctica, Rev. Geophys., 50, RG1004, doi:10.1029/2011RG000363, 2012.

Campbell, J. R., Hlavka, D. L., Welton, E. J., Flynn, C. J., Turner, D. D., Spinhirne, J. D., Scott, V. S., and Hwang, I. H.: Full-Time, Eye-Safe Cloud and Aerosol Lidar Observation at Atmospheric Radiation Measurement Program Sites: Instruments and Data Processing, J. Atmos. Ocean. Technol., 19, 431-442, doi:10.1175/1520-0426(2002)019<0431:FTESCA>2.0.CO;2, 2002.
Cao, N., Zhu, C., Kai, Y., and Yan, P.: A method of background noise reduction in lidar data, Appl. Phys. B, 113, 115-123, doi:10.1007/s00340-013-5447-9, 2013.

de Haij, M., Wauben, W., and Klein Baltink, H.: Determination of mixing layer height from ceilometer backscatter profiles, edited by: Slusser, J. R., Schäfer, K., and Comerón, A., Remote Sens., 63620R-63620R-12, doi:10.1117/12.691050, 2006.

Emeis, S.: Surface-Based Remote Sensing of the Atmospheric Boundary Layer, Springer Science \& Business Media, doi:10.1007/978-90-481-9340-0, ISBN-13: 978-90-481-9339-4, 174 pp., 2010.

Emeis, S., Schäfer, K., and Münkel, C.: Surface-based remote sensing of the mixing-layer height - a review, Meteorol. Zeitschrift, 17, 621-630, doi:10.1127/0941-2948/2008/0312, 2008.

Emeis, S., Schäfer, K., and Münkel, C.: Observation of the structure of the urban boundary layer with different ceilometers and validation by RASS data, Meteorol. Z., 18, 149-154, doi:10.1127/0941-2948/2009/0365, 2009.

Emeis, S., Schäfer, K., Münkel, C., Friedl, R., and Suppan, P.: Evaluation of the Interpretation of Ceilometer Data with RASS and Radiosonde Data, Bound.-Lay. Meteorol., 143, 2535, doi:10.1007/s10546-011-9604-6, 2011a.

Emeis, S., Forkel, R., Junkermann, W., Schäfer, K., Flentje, H., Gilge, S., Fricke, W., Wiegner, M., Freudenthaler, V., Groß, S., Ries, L., Meinhardt, F., Birmili, W., Münkel, C., Obleitner, F., and Suppan, P.: Measurement and simulation of the 16/17 April 2010 Eyjafjallajökull volcanic ash layer dispersion in the northern Alpine region, Atmos. Chem. Phys., 11, 2689-2701, doi:10.5194/acp-11-2689-2011, 2011b.

Eresmaa, N., Härkönen, J., Joffre, S. M., Schultz, D. M., Karppinen, A., and Kukkonen, J.: A Three-Step Method for Estimating the Mixing Height Using Ceilometer Data from the Helsinki Testbed, J. Appl. Meteorol. Climatol., 51, 2172-2187, doi:10.1175/JAMC-D-12-058.1, 2012.

Gregorio, E., Rocadenbosch, F., and Comeron, A.: Design methodology of a ceilometer lidar prototype, in 2007 IEEE International Geoscience and Remote Sensing Symposium, 3162-3165, IEEE, doi:10.1109/IGARSS.2007.4423516, 23-28 July 2007.

Grimmond, S: London Urban Micrometeorological Observatory, LUMO, available at: http://www.met.reading.ac.uk/micromet/ LUMA/request.html, 2016.

Haeffelin, M., Barthès, L., Bock, O., Boitel, C., Bony, S., Bouniol, D., Chepfer, H., Chiriaco, M., Cuesta, J., Delanoë, J., Drobinski, P., Dufresne, J.-L., Flamant, C., Grall, M., Hodzic, A., Hourdin, F., Lapouge, F., Lemaître, Y., Mathieu, A., Morille, Y., Naud, C., Noël, V., O'Hirok, W., Pelon, J., Pietras, C., Protat, A., Romand, B., Scialom, G., and Vautard, R.: SIRTA, a ground-based atmospheric observatory for cloud and aerosol research, Ann. Geophys., 23, 253-275, doi:10.5194/angeo-23-253-2005, 2005.

Haeffelin, M., Bergot, T., Elias, T., Tardif, R., Carrer, D., Chazette, P., Colomb, M., Drobinski, P., Dupont, E., Dupont, J.-C., Gomes, L., Musson-Genon, L., Pietras, C., Plana-Fattori, A., Protat, A., Rangognio, J., Raut, J.-C., Rémy, S., Richard, D., Sciare, J., and Zhang, X.: PARISFOG: Shedding New Light on Fog Physical Processes, B. Am. Meteorol. Soc., 91, 767-783, doi:10.1175/2009BAMS2671.1, 2010.

Haeffelin, M., Angelini, F., Morille, Y., Martucci, G., Frey, S., Gobbi, G. P., Lolli, S., O’Dowd, C. D., Sauvage, L., XuerefRémy, I., Wastine, B., and Feist, D. G.: Evaluation of Mixing- 
Height Retrievals from Automatic Profiling Lidars and Ceilometers in View of Future Integrated Networks in Europe, Bound.Lay. Meteorol., 143, 49-75, doi:10.1007/s10546-011-9643-z, 2012.

Heese, B., Flentje, H., Althausen, D., Ansmann, A., and Frey, S.: Ceilometer lidar comparison: backscatter coefficient retrieval and signal-to-noise ratio determination, Atmos. Meas. Tech., 3, 1763-1770, doi:10.5194/amt-3-1763-2010, 2010.

Hervo, M., Poltera, Y., and Haefele, A.: An empirical method to correct for temperature-dependent variations in the overlap function of CHM15k ceilometers, Atmos. Meas. Tech., 9, 2947-2959, doi:10.5194/amt-9-2947-2016, 2016.

Hopkin, E., Illingworth, A., Westbrook, C., Charlton-Perez, C., and Ballard, S.: Calibration of the Met Office Network using the Cloud Method, ISARS, Varna, Bulgaria, 6-9 June 2016.

Illingworth, A. J., Hogan, R. J., O’Connor, E. J., Bouniol, D., Delanoë, J., Pelon, J., Protat, A., Brooks, M. E., Gaussiat, N., Wilson, D. R., Donovan, D. P., Baltink, H. K., van Zadelhoff, G.J., Eastment, J. D., Goddard, J. W. F., Wrench, C. L., Haeffelin, M., Krasnov, O. A., Russchenberg, H. W. J., Piriou, J.-M., Vinit, F., Seifert, A., Tompkins, A. M., and Willén, U.: Cloudnet, B. Am. Meteorol. Soc., 88, 883-898, doi:10.1175/BAMS-88-6-883, 2007.

Illingworth, A. J., Cimini, D., Gaffard, C., Haeffelin, M., Lehmann, V., Löhnert, U., O’Connor, E. J., and Ruffieux, D.: Exploiting existing ground-based remote sensing networks to improve high resolution weather forecasts, B. Am. Meteorol. Soc., 96, 21072125, doi:10.1175/BAMS-D-13-00283.1, 2015.

Knippertz, P. and Stuut, J.-B. W.: Mineral Dust: A Key Player in the Earth System, edited by: Knippertz, P. and Stuut, J.-B. W., Springer, the Netherlands, doi:10.1007/978-94-017-8978-3, ISBN-13: 978-94-017-8978-3, 509 pp., 2014.

Madonna, F., Amato, F., Vande Hey, J., and Pappalardo, G.: Ceilometer aerosol profiling versus Raman lidar in the frame of the INTERACT campaign of ACTRIS, Atmos. Meas. Tech., 8, 2207-2223, doi:10.5194/amt-8-2207-2015, 2015.

Manninen, A. J., O'Connor, E. J., Vakkari, V., and Petäjä, T.: A generalised background correction algorithm for a Halo Doppler lidar and its application to data from Finland, Atmos. Meas. Tech., 9, 817-827, doi:10.5194/amt-9-817-2016, 2016.

Markowicz, K. M., Flatau, P. J., Kardas, A. E., Remiszewska, J., Stelmaszczyk, K., and Woeste, L.: Ceilometer Retrieval of the Boundary Layer Vertical Aerosol Extinction Structure, J. Atmos. Ocean. Technol., 25, 928-944, doi:10.1175/2007JTECHA1016.1, 2008.

Martucci, G., Milroy, C., and O'Dowd, C. D.: Detection of Cloud-Base Height Using Jenoptik CHM15K and Vaisala CL31 Ceilometers, J. Atmos. Ocean. Technol., 27, 305-318, doi:10.1175/2009JTECHA1326.1, 2010.

Mattis, I. and Wagner, F.: Glossary of lidar and ceilometer variables, available at: http://www.eumetnet.eu/sites/default/files/ ALC_glossary.pdf (last access: 7 August 2016), 2014.

Marzano, F. S., Mereu, L., Montopoli, M., Cimini, D., and Martucci, G.: Volcanic Ash Cloud Observation using Ground-based Ka-band Radar and Near-Infrared Lidar Ceilometer during the Eyjafjallajökull eruption, AG, 57, 1-7, doi:10.4401/ag-6634, 2014.

McKendry, I. G., van der Kamp, D., Strawbridge, K. B., Christen, A., and Crawford, B.: Simultaneous observa- tions of boundary-layer aerosol layers with CL31 ceilometer and 1064/532 nm lidar, Atmos. Environ., 43, 5847-5852, doi:10.1016/j.atmosenv.2009.07.063, 2009.

Met Office: Met Office LIDARNET Benson Vaisala CL31 ceilometer cloud base and backscatter data, Centre for Environmental Data Analysis, 10 August 2016, availabe at: http://catalogue ceda.ac.uk/uuid/cc1a21f1973743949bd9c8cb4fe2d97f, 2015.

Mielonen, T., Aaltonen, V., Lihavainen, H., Hyvärinen, A.-P., Arola, A., Komppula, M., and Kivi, R.: Biomass Burning Aerosols Observed in Northern Finland during the 2010 Wildfires in Russia, Atmosphere (Basel), 4, 17-34, doi:10.3390/atmos4010017, 2013.

Münkel, C., Eresmaa, N., Räsänen, J., and Karppinen, A.: Retrieval of mixing height and dust concentration with lidar ceilometer, Bound.-Lay. Meteorol., 124, 117-128, doi:10.1007/s10546-0069103-3, 2007.

Münkel, C., Emeis, S., Schäfer, K., and Brümmer, B.: Improved near-range performance of a low-cost one lens lidar scanning the boundary layer, Proc. SPIE, 7475, 1-10, doi:10.1117/12.830397, 2009.

Nemuc, A., Stachlewska, I. S., Valilescu, J., Górska, A., Nicolae, D., and Talianu, C.: Optical Properties of Long-Range Transported Volcanic Ash over Romania and Poland During Eyjafjallajökull Eruption in 2010, Acta Geophys., 62, 350-366 doi:10.2478/s11600-013-0180-7, 2014.

O'Connor, E. J., Illingworth, A. J., and Hogan, R. J.: A Technique for Autocalibration of Cloud Lidar, J. Atmos. Ocean. Technol., 21, 777-786, doi:10.1175/15200426(2004)021<0777:ATFAOC>2.0.CO;2, 2004.

O'Connor, E. J., Hogan, R. J., and Illingworth, A. J.: Retrieving Stratocumulus Drizzle Parameters Using Doppler Radar and Lidar, J. Appl. Meteorol., 44, 14-27, doi:10.1175/JAM-2181.1, 2005.

Rogers, R. R., Lamoureux, M.-F., Bissonnette, L. R., and Peters, R. M.: Quantitative Interpretation of Laser Ceilometer Intensity Profiles, J. Atmos. Ocean. Technol., 14, 396-411, doi:10.1175/1520-0426(1997)014<0396:QIOLCI>2.0.CO;2, 1997.

Selvaratnam, V., Ordnez, C., and Adam, M.: Comparison of planetary boundary layer heights from Jenoptik ceilometers and the Unified Model, Forecast. Res. Tech. Rep. No. 605, 24, 2015.

SIRTA: Site Instrumental de Recherche par Télédétection Atmosphérique, available at: http://www.sirta.fr, 2016.

Sokół, P., Stachlewska, I., Ungureanu, I., and Stefan, S.: Evaluation of the boundary layer morning transition using the CL-31 ceilometer signals, Acta Geophys., 62, 367-380, doi:10.2478/s11600-013-0158-5, 2014.

Stachlewska, I. S., Piądłowski, M., Migacz, S., Szkop, A., Zielińska, A. J., and Swaczyna, P. L.: Ceilometer observations of the boundary layer over Warsaw, Poland, Acta Geophys., 60, 1386-1412, doi:10.2478/s11600-012-0054-4, 2012.

Sundström, A.-M., Nousiainen, T., and Petäjä, T.: On the Quantitative Low-Level Aerosol Measurements Using CeilometerType Lidar, J. Atmos. Ocean. Technol., 26, 2340-2352, doi:10.1175/2009JTECHA1252.1, 2009.

Tang, G., Zhang, J., Zhu, X., Song, T., Münkel, C., Hu, B., Schäfer, K., Liu, Z., Zhang, J., Wang, L., Xin, J., Suppan, P., and Wang, Y.: Mixing layer height and its implications for air pol- 
lution over Beijing, China, Atmos. Chem. Phys., 16, 2459-2475, doi:10.5194/acp-16-2459-2016, 2016.

Tsaknakis, G., Papayannis, A., Kokkalis, P., Amiridis, V., Kambezidis, H. D., Mamouri, R. E., Georgoussis, G., and Avdikos, G.: Inter-comparison of lidar and ceilometer retrievals for aerosol and Planetary Boundary Layer profiling over Athens, Greece, Atmos. Meas. Tech., 4, 1261-1273, doi:10.5194/amt-4-1261-2011, 2011.

Vande Hey, J. D.: A Novel Lidar Ceilometer: Design, Implementation and Characterisation, Springer, doi:10.1007/978-3-31912613-5, ISBN-13: 978-3-319-12613-5, 158 pp., 2014.

van der Kamp, D.: Ceilometer observations of Vancouver's urban boundary layer: validation and mixed-layer height estimation, Master's thesis, University of British Columbia, available at: https://open.library.ubc.ca/cIRcle/collections/ubctheses/ 24/items/1.0066572, doi:10.14288/1.0066572, 120 pp., 2008.

van der Kamp, D. and McKendry, I.: Diurnal and Seasonal Trends in Convective Mixed-Layer Heights Estimated from Two Years of Continuous Ceilometer Observations in Vancouver, BC, Bound.Lay. Meteorol., 137, 459-475, doi:10.1007/s10546-010-9535-7, 2010.

Weitkamp, C.: Lidar: Range-Resolved Optical Remote Sensing of the Atmosphere, Springer, New York, doi:10.1007/b106786, ISBN-13: 978-0-387-25101-1, 456 pp., 2005.
Welch, B. L.: The generalization of "Student's" problem when several different population variances are involved, Biometrika, 34, 28-35, doi:10.1093/biomet/34.1-2.28, 1947.

Wiegner, M. and Gasteiger, J.: Correction of water vapor absorption for aerosol remote sensing with ceilometers, Atmos. Meas. Tech., 8, 3971-3984, doi:10.5194/amt-8-3971-2015, 2015.

Wiegner, M., Gasteiger, J., Groß, S., Schnell, F., Freudenthaler, V., and Forkel, R.: Characterization of the Eyjafjallajökull ashplume: Potential of lidar remote sensing. Phys. Chem. Earth, 4546, 79-86. doi:10.1016/j.pce.2011.01.006, 2012.

Wiegner, M., Madonna, F., Binietoglou, I., Forkel, R., Gasteiger, J., Geiß, A., Pappalardo, G., Schäfer, K., and Thomas, W.: What is the benefit of ceilometers for aerosol remote sensing? An answer from EARLINET, Atmos. Meas. Tech., 7, 1979-1997, doi:10.5194/amt-7-1979-2014, 2014.

Xie, C. and Zhou, J.: Method and analysis of calculating signal-tonoise ratio in lidar sensing, Spie, Proc. SPIE 5832, Opt. Technol. Atmos. Ocean. Environ. Stud., 738, doi:10.1117/12.619881, 2005. 